\title{
XLIX. Experiments on the propagation of longitudinal waves of magnetic flux along iron wires and rods
}

Thomas R. Lyle M.A. Sc.D. \& J.M. Baldwin M.A. B.Sc.

To cite this article: Thomas R. Lyle M.A. Sc.D. \& J.M. Baldwin M.A. B.Sc. (1906) XLIX.

Experiments on the propagation of longitudinal waves of magnetic flux along iron wires and rods, Philosophical Magazine Series 6, 12:71, 433-468, DOI: 10.1080/14786440609463558

To link to this article: http://dx.doi.org/10.1080/14786440609463558

曲 Published online: 16 Apr 2009.

Submit your article to this journal $[\pi$

Џll Article views: 2

Q View related articles $\longleftarrow$

Citing articles: 4 View citing articles $\square$ 


\title{
PHILOSOPHICAL MAGAZINE
}

\author{
AND \\ JOURNAL OF SCIENCE.
}

[SIXTH SERIES.]

NOVEMBER 1906.

XLIX. Experiments on the Propagation of Longitudinal Waves of Magnetic Flux along Iron Wires and Rods. By Thomas R. Liver, M.A., Sc.D., Professor of Natural Philosophy in the University of Melbourne, and J. M. Baldwis, M.A., B.Sc.*

1. THE following experiments were undertaken in order to investigate the changes in the Fourier characteristics of waves of magnetic flux as they travel along iron wires and rods. In all cases these flux-waves were started at the middle points of the rods or wires by sending alternating currents through short coaxial solenoids placed there.

The subject has already been attacked in different ways by several experimenters, and from the difference in phase of the flux oscillations at two points a so-called "velocity of magnetization" has been obtained from the formula,

$$
v=\frac{2 \pi l}{\phi \mathrm{T}}
$$

where $\quad v=$ the "velocity of magnetization,"

$\mathrm{T}=$ the period of the oscillations,

$\phi=$ the difference in phase at two points $l$ centimetres apart.

Oberbeck $\uparrow$ worked with rods and bundles of wires, in some cases $40 \mathrm{~cm}$, in others 1 metre long, and by means of a

* Communicated by the Physical Society : read January 26, 1906.

$\dagger$ A. Oberbeck, Wied. Ann. vol. xxii. p. 73 (1884).

Phil. Mag. S. 6. Vol. 12. No. 71. Nov. 1906.2 F 


\section{Prof. Lyle and $\mathrm{Mr}$. Baldwin on Propagation of}

dynamometer measured the phase-difference of the currents induced in two short solenoids placed at various distances apart on the rod. This was equal to the phase-difference of the two resultant fluxes at the points, provided the timeconstants of the circuits of the two solenoids were negligible.

The "velocity" deduced varied from $232,300 \mathrm{~cm}$./sec. for 64 steel wires each $1.8 \mathrm{~mm}$. diam., to $4410 \mathrm{~cm}$./sec. for a steel $\operatorname{rod} 12 \mathrm{~mm}$. diam., a result which indicates the great influence of eddy currents. He found that the "velocity" was not directly influenced by the character of the iron of the rod

The amplitude $\mathbf{F}_{x}$ of the resultant flux at different points he found to be given by the formula

$$
\mathrm{F}_{x}=\mathrm{F}_{0} e^{-\lambda x}
$$

where $\lambda$ is to a first approximation a constant depending on the material of the bar, but independent of the area of its cross-section.

The values he found for $\lambda$ when $x$, the distance from the centre of the magnetizing solenoid, is in centimetres, were

$$
\begin{aligned}
& \cdot 1027, \cdot 1017, \cdot 1007 \text { for soft iron, } \\
& \cdot 148, \quad \text { for hard iron, } \\
& \cdot 1451, \cdot 1616, \cdot 1637 \text { for steel. }
\end{aligned}
$$

One frequency only was used.

Trouton * attempted to obtain stationary flux-waves by the interference of two trains of waves travelling in opposite directions round a ring of iron wires, the two trains being produced by an alternating current of known frequency circulating in a short solenoid looped on the ring. He concluded, however, that the effects which he observed were not due to interference but to some peculiarity of the ring.

Zenneck $\dagger$, assuming the permeability $\mu$ and the leakage coefficient $\lambda=-d \mathrm{~F} / \mathrm{F} d x$ constants, where $\mathrm{F}$ is the flux at $x$, obtained from theory expressions for the flux-waves at different points along iron cylinders in terms of the initial Hux where $x=0$, and to verify his theoretical conclusions used a Braun tube to determine the relative amplitudes and phases of the flux oscillations at any two points.

For thick wires (some millimetres in diameter) he found that the "velocity" and the leakage coefficient $\lambda$ increased with frequency, while for wires less than $1 \mathrm{~mm}$. in diam.

* F. T. Trouton, ' Nature,' vol. xlv. p. 42 (1891).

†.J. Zenneck, Ann. der Phys. vol. ix. p. 497 (1902), and vol. x. p. 845 (1903). 
they were, to a first approximation, independent of the frequency.

More recently Perkins*, working at a frequency of 60 , has measured by means of a quadrant-electrometer the amplitude and phase, at different points along an iron bar, of the flux oscillation which had been started in the usual way at the centre. The bar used was 1 metre long, $2.83 \mathrm{~cm} .^{2}$ in cross-section, and observations were made over a range of $25 \mathrm{~cm}$. from its centre.

The phase was found to change less rapidly as the distance from the magnetizing-coil increased, and the "velocity of magnetization" obtained varied from

$7500 \mathrm{~cm}$. $/ \mathrm{sec}$. at the centre

to $24000 \mathrm{~cm}$. $/ \mathrm{sec}$. at $24 \mathrm{~cm}$. from the centre.

The curve he obtained showing the relation between the lag in phase of the flux at any point and the distance of the point from the magnetizing-coil agrees in general character with the corresponding small portions of the curves obtained by us.

The same problem has been theoretically discussed by Thomson $\dagger$. He assumes that the permeability is constant for all values of the induction, and takes no account of the lag in phase of the induction behind the magnetizing force. As the flux-density or induction diminishes with great rapidity as we pass down the bar, and as both the permeability and the lag in phase of the induction vary within wide limits for different values of the latter, the theoretical conclusions arrived at on the assumption that one of these two quantities is constant and the other negligible, can scarcely be expected to be realized in practice.

2. In all the experimental investigations hitherto carried out on this subject, the range along the rod over which it was possible to determine even roughly the amplitude and phase of the flux oscillations at different points was limited, and the apparent behaviour over a short range afforded a very doubtful and misleading description of the whole phenomenon. No attempt, moreover, was made to determine the change of form of the flux-waves as they passed along the bar.

For this investigation the wave-tracer + designed by one of us is peculiarly well suited, as it enables us to determine

* H. A. Perkins, Amer. Jour. Sci. vol. xviii. p. 165 (1904).

$\dagger$ J. J. Thomson, 'Recent Researches,' p. 302.

T. R. Lyle, "Wave-Tracer and Analyser," Phil. Mag. vol. vi. p. 549 (1903). 
completely, not only current and E.M.F. waves, but also fluxwaves over a wide range of amplitudes.

For instance, by its means can be accurately determined flux-waves whose amplitudes range from very large values down to a fraction of a single magnetic line; and by subjecting its readings to harmonic analysis we have been able to obtain the Fourier characteristics of the resultant flux oscillations at all points along rods of iron or steel, $\frac{1}{4}$ in. in diam. and 10 feet long, which have been magnetized by an alternating current circulating in a short solenoid placed at their middle points, when the amplitude of the flux-density at the centre was as low as 10,000 .

3 . The experiments, of which the results will be given below, were made on

A. A long rod of Lowmoor iron $\frac{1}{4}$ in. in diameter.

B. A long rod of silver steel $\frac{1}{4}$ in. in diameter.

C. A long iron wire $\frac{1}{6}$ in. in diameter.

D. A bundle of 185 charcoal iron wires, each $079 \mathrm{~cm}$, in diameter, $370 \mathrm{~cm}$. long, tightly taped together so as to form a circular cylinder.

$d_{1}$. A bundle of 46 of the wires from $\mathrm{D}$.

$d_{2}$. A bundle of 12 of the wires from $\mathrm{D}$.

In each case at the middle point of the rod or bundle a short coaxial solenoid was placed, and through it an alternating current obtained from a rotary converter supplied with direct current from storage-cells was sent.

The magnetizing-current wave and the resultant flux-waves, crossing the sections of the bar or bundle at different points along its length, were quantitatively determined by the wavetracer using the galvanometer method ${ }^{*}$ described in the paper already quoted. The wave forms so obtained were subjected to harmonic analysis, the results of which are given in the Tables below. Some of the more interesting of the results of the investigation are also exhibited by means of curves.

The arrangement of the apparatus, the method of experiment, and the reduction of the observations were the same in all essential features as that fully described in a former paper $\dagger$ by one of us. Instead of the fixed secondary coil of 5 or 10 turns wound on the iron rings used in the experiments just quoted, three small search-coils were used. One of these, wound close to the rod or bundle, was fixed at the

* T. R. Lyle, "Wave-Tracer and Analyser," Phil. Mag. vol. vi. p. 549 (1903).

$\dagger$ T. R. Lyle, "Variation of Magnetic Hysteresis with Frequency," Phil. Mag, vol. ix. p. 102 (1905). 
centre of the magnetizing solenoid; while the other two, of 166 and 805 turns respectively, could be moved from point to point along the rod, the one with the larger number of turns being used for exploring the rod at points near its ends.

During each series of experiments the magnetizing current and the rate of alternation were lept as constant as possible, and a continuous record was made by a chronograph of the times taken for every 200 periods.

The method of procedure in any one series of experiments was as follows:-The speed of the rotary converter having been adjusted to the desired value by means of resistances in the field circuit, or, if necessary, by changing the number of storage-cells used on its direct-current side, the magnetizing current drawn from its alternating side was adjusted by means of resistances to the desired value, and allowed to run until all conductors had attained a steady temperature.

By means of the wave-tracer equi-spaced ordinates of the magnetizing current wave sufficient in number to determine it were now taken. Then the corresponding ordinates of the flux-waves at the centre and at different points along the rod were obtained, and finally the ordinates of the current wave were redetermined to serve as a check on the constancy of the magnetizing force during the run.

Each set of ordinates was now subjected to harmonic analysis and the results affected by their proper factors* to reduce them either to current or flux, as the case might be, in absolute measure.

Three frequencies were used with specimens $\mathbf{A}$ and $\mathrm{C}$, and two with specimen $\mathrm{D}$, the central or initial flux being approximately the same for the different frequencies in any one specimen. With $A$ and $D$ additional series were obtained at one of the frequencies already used, but with different initial fluxes. For each of the other specimens $B, d_{1}$, and $d_{2}$, the results of one series of experiments only are given below.

For all the specimens but $d_{1}$ and $d_{2}$, by means of a ballistic galvanometer, using the method of reversals, the fluxes at different points along their lengths, due to a continuous magnetizing current in the central solenoid, were determined when the continuous current was such as produced at the centre a flux approximately equal to the amplitude of the central alternating flux previously used.

In addition the statical permeability of the material of each of the specimens for different values of the flux density was obtained by the method of reversals, a long solenoid being used to carry the magnetizing current.

* T. R. Lyle, "Wave-Tracer and Ainlyser," Phil. Mag. rol. vi. p. 549 (1903). 
The specific resistance of each specimen was also measured.

In the case of specimen A, after all the observations that were deemed necessary for its full length had been taken, it was shortened by successive steps by cutting off each time equal lengths from both ends; each reduced length was then investigated for one frequency and one central flux.

4. We now proceed to give the results of the different experiments.

For every series the Fourier characteristics of the magnetizing current wave and of the resultant flux wave at different distances from the centrally placed magnetizing solenoid will be given in tabular form, and curves will be given showing how the phase, and the natural logarithm of the amplitude, of the first harmonic of the resultant flux varies as we pass along the specimen from the centre to the end. In the tables will also be given for different points the values of the leakage coefficient $\lambda_{1}$ of the amplitude $f_{1}$ of the first harmonic of the flux, where

$$
\begin{aligned}
\lambda_{1} & =-\frac{1}{f_{1}} \frac{d f_{1}}{d x}=-\frac{d}{d x}\left(\log _{e} f_{1}\right) \\
& =\frac{\left(\log _{e} f_{1}\right)_{x}-\left(\log _{e} f_{1}\right)_{x^{\prime}}}{x^{\prime}-x}(\mathrm{q} \cdot \mathrm{p} .)
\end{aligned}
$$

at the point $\frac{1}{2}\left(x+x^{\prime}\right)$, where $x$ and $x^{\prime}$ are two adjacent points at which $f_{1}$ has been determined. By means of the last expression the values of $\lambda_{1}$ have been calculated, and they are placed in the tables between the two adjacent rows of characteristics from which they have been obtained.

In the tables $\mathrm{T}$ will represent the period of the alternating current and flux in any one experiment, $x$ the distance from the centre of the specimen (and of the magnetizing solenoid) of the section across which the resultant flux $F$ (in absolute measure) passes, and $\mathrm{C}$ the magnetizing current used during one series (also in absolute measure).

No harmonics higher than the 5th will be given, though they were determined in all cases, unless their amplitudes were below one per cent. of the amplitude of the corresponding first harmonic.

The galvanometer circuit of the wave-tracer when searchcoil No. 3 was used had a very small time constant which was allowed for.

[Note.-The figures given in the tables are the results from the individual experiments. No smoothing of values has been resorted to, though a small error in the setting of the search-coil would make a large error in the result.] 
5. Details of Specimen A.

A straight cylindrical rod of Lowmoor iron.

Length $=267 \mathrm{cms}$.

Diameter $=\cdot 644 \mathrm{~cm}$. Section $=\cdot 3260 \mathrm{sq} . \mathrm{cm}$.

Length of magnetizing solenoid ........... $2 \cdot 54 \mathrm{~cm}$.

Radial depth of $" \quad, \quad \ldots . \ldots . . . .2 \cdot 40 \mathrm{~cm}$.

Mean radius of $, \quad, \quad \ldots \ldots \ldots . .1 \cdot 70 \mathrm{~cm}$.

No. of turns on $, \quad, \quad$........... 240.

Specific resistance of the iron $=1 \cdot 140 \times 10^{4}$.

Statical Permeability for different Inductions.

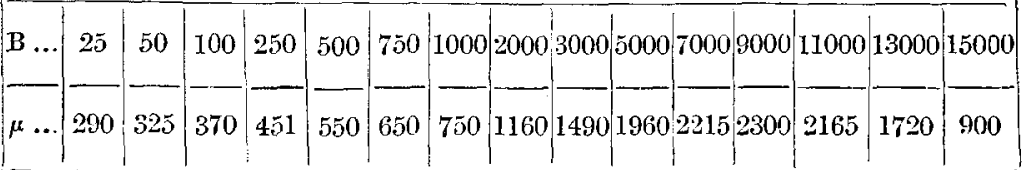

The analysed results of the alternating current experiments with this specimen are given in the following tables (I. to IV.), and the values of the Hux and leakage coefficients at different points due to a continuous magnetizing force at the centre of the rod are given in Table $V$.

Table I.-Specimen A. T=.053 q.p.

\begin{tabular}{|c|c|c|c|c|c|c|c|c|c|}
\hline$x$. & $\mathrm{T}$. & $f_{1}$ & $f_{3}$. & $f_{y}$ & $\theta$. & $\beta_{i:}$ & $\beta_{v}$. & $\theta_{x}-\theta_{0}$ & $\lambda_{1}$. \\
\hline $0 \ldots$ & .0537 & 3798 & $51 \cdot 7$ & $23 \cdot 3$ & $30 \cdot 64$ & 9335 & $31 \cdot 85$ & 0 & \\
\hline $5 \ldots$ & .0536 & 2618 & $70 \cdot 1$ & 140 & $41 \cdot 42$ & 92.04 & $82 \cdot 19$ & $10 \cdot 78$ & 07 \\
\hline $10 \ldots$ & 0534 & 1710 & $54 \cdot 8$ & $7 \cdot 97$ & 5359 & 9235 & $29 \cdot 17$ & 2295 & 08 \\
\hline $15 \ldots$ & .0531 & 1131 & $37 \cdot 6$ & $5 \cdot 54$ & 6441 & $94 \cdot 68$ & $31 \cdot 68$ & 3377 & 08 \\
\hline $20 \ldots$ & .0532 & 738 & $23 \cdot 4$ & 1.85 & 7446 & 98.09 & $31 \cdot 03$ & 43882 & 0855 \\
\hline $30 \ldots$ & $05 \check{18}$ & $269 \cdot 1$ & 6.83 & $\ldots$ & $93 \cdot 21$ & 106.06 & $\cdots$ & $62: 57$ & 1009 \\
\hline $40 \ldots$ & 0528 & 83.8 & 1.50 & 0.49 & 105.42 & $109 \cdot 5^{2}$ & 38.67 & $74 \cdot 78$ & $\cdot 1167$ \\
\hline $50 \ldots$ & 0530 & 270 & 0.28 & $\ldots$ & $107 \cdot 27$ & $\ldots$ & $\ldots$ & $76 \cdot 63$ & $\cdot 1134$ \\
\hline $60 \ldots$ & 0526 & 951 & $\ldots$ & $\ldots$ & 101.97 & $\ldots$ & $\ldots$ & $71 \cdot 33$ & $\cdot 1042$ \\
\hline $70 \ldots$ & -0515 & 4388 & $\ldots$ & $\ldots$ & $92 \cdot 31$ & $\ldots$ & $\ldots$ & $61 \cdot 67$ & 0775 \\
\hline $80 \ldots$ & .0526 & 2583 & $\ldots$ & $\ldots$ & $84 \cdot 80$ & $\ldots$ & $\ldots$ & $54 \cdot 16$ & 0529 \\
\hline $100 \ldots$ & -0527 & $1 \cdot 175$ & $\cdots$ & $\cdots$ & $78 \cdot 00$ & $\ldots$ & $\ldots$ & $47 \cdot 36$ & $\mid 0394$ \\
\hline $120 \ldots$ & .0528 & 0.604 & $\cdots$ & $\ldots$ & $74 \cdot 61$ & $\ldots$ & $\ldots$ & $43 \cdot 97$ & 0333 \\
\hline $130 \ldots$ & .0528 & $0 \cdot 323$ & $\cdot 0058$ & .0035 & $69 \cdot 64$ & $133 \cdot 3$ & $\ldots$ & 39.00 & .0626 \\
\hline
\end{tabular}


TABLE II.-Specimen A. T $=\cdot 053$ q.p.

$\mathrm{C}=\cdot 2154 \sin \omega t+\cdot 01077 \sin 3(\omega t-55 \cdot 82)+\cdot 00072 \sin 5(\omega t-72)$.

$\mathbf{F}=f_{1} \sin (\omega t-\theta)+f_{3} \sin 2\left(\omega t-\theta-\beta_{3}\right)+f_{5} \sin 5\left(\omega t-\theta-\beta_{5}\right)$.

\begin{tabular}{|c|c|c|c|c|c|c|c|c|c|}
\hline$x$. & ג. & $f_{1}$. & $f_{3}$. & $f_{5}$. & $\theta$. & $\beta_{3}$. & $\beta_{\overline{3}}$. & $\theta_{x}-\theta_{0}$ & $\lambda_{1}$. \\
\hline 0. & .0530 & 5009 & 1256 & 4305 & 3072 & $96 \cdot 80$ & $37 \cdot 6$ & 0 & \\
\hline 10. & .0530 & 2232 & $109 \cdot 3$ & 237 & $54 \cdot 80$ & $88 \cdot 69$ & 25.2 & $24 \cdot 08$ & .0809 \\
\hline 20 .. & 0530 & 9851 & $40 \cdot 5$ & 438 & $76 \cdot 18$ & $89 \cdot 84$ & 28.0 & $45 \cdot 46$ & 081 \\
\hline $30 .$. & $\cdot 0532$ & $393 \cdot 4$ & $9 \cdot 46$ & $\ldots$ & 94.87 & $95 \cdot 80$ & ... & $64 \cdot 15$ & 091 \\
\hline 40. & .0532 & $132 \cdot 1$ & $1 \cdot 64$ & $\cdots$ & 109.27 & 10673 & $\ldots$ & 78.55 & $\cdot 1091$ \\
\hline 50. & .0532 & $42 \cdot 0$ & $\ldots$ & $\ldots$ & $113 \cdot 64$ & $\ldots$ & $\cdots$ & $82 \cdot 92$ & $\cdot 114$ \\
\hline $60 .$. & .0532 & $14 \cdot 32$ & $0 \cdot 15$ & .. & $109 \cdot 13$ & 158.4 & $\ldots$ & $78 \cdot 41$ & $\cdot 1076$ \\
\hline $70 .$. & $\cdot 0531$ & $6 \cdot 16$ & $0 \cdot 10$ & $\ldots$ & 98.23 & 177.2 & $\ldots$ & 67.51 & $\cdot 0843$ \\
\hline $80 .$. & $\cdot 0527$ & $3 \cdot 48$ & 0.06 & $\ldots$ & 89.37 & $186 \cdot 6$ & $\cdots$ & $58 \cdot 65$ & $\cdot 0571$ \\
\hline $100 .$. & $\cdot 0525$ & 1.572 & 0.027 & $\cdots$ & $80 \cdot 84$ & 1959 & $\cdots$ & $50 \cdot 12$ & $\cdot 0397$ \\
\hline 120. & $\cdot 0526$ & 0.797 & $0 \cdot 017$ & $\cdots$ & 75.94 & 1968 & $\ldots$ & $45 \cdot 22$ & 0340 \\
\hline $130 .$. & $\cdot 0526$ & 0.428 & $0 \cdot 009$ & $\cdots$ & $71 \cdot 04$ & $203 \cdot 0$ & $\ldots$ & $40 \cdot 32$ & 0622 \\
\hline
\end{tabular}

TAbLe III._Specimen A. T=.032 q.p.

\begin{tabular}{|c|c|c|c|c|c|c|c|c|c|}
\hline \multicolumn{10}{|c|}{$\begin{array}{l}\mathbf{C}=\cdot 1649 \sin \omega t+\cdot 00655 \sin 3(\omega t-58 \cdot 61)+\cdot 00096 \sin 5(\omega t-36 \cdot 1) \\
\mathrm{F}=f_{1} \sin (\omega t-\theta)+f_{3} \sin 3\left(\omega t-\theta-\beta_{3}\right)+f_{5} \sin 5\left(\omega t-\theta-\beta_{\overline{5}}\right)\end{array}$} \\
\hline$x$ & T. & $f_{1}$. & $f_{3}$. & $f_{5}$. & $\theta$. & $\beta_{3}$ & $\beta_{\bar{n}}$. & $\theta_{x}-\theta_{n}$ & $\lambda_{2}$ \\
\hline $0 .$. & .0320 & 3730 & 78.14 & $26 \cdot 8$ & $33 \cdot 04$ & $89 \cdot 39$ & 32.02 & 0 & .080 \\
\hline 10. & .0320 & 1530 & 662 & 142 & 5970 & 8688 & $24 \cdot 30$ & 2666 & .008 \\
\hline $20 \ldots$ & $0: 1 \%$ & $596 \cdot 6$ & $17 \cdot 1$ & $\cdots$ & 84.89 & $91 \cdot 19$ & $\ldots$ & 51.85 & OSI \\
\hline $30 .$. & $.03 \div 0$ & 1920 & 36 & $\ldots$ & $107 \cdot 21$ & $104 \cdot 68$ & $\ldots$ & $74 \cdot 17$ & .1 .289 \\
\hline $40 .$. & 0320 & $52 \cdot 9$ & 0.83 & $\ldots$ & 12274 & $110 \cdot 30$ & $\ldots$ & $89 \cdot 70$ & 1.051 \\
\hline $50 .$. & 0321 & $15 \cdot 14$ & $0 \cdot 12$ & $\ldots$ & $121 \cdot 88$ & 136.54 & $\cdots$ & $88 \cdot 84$ & .1097 \\
\hline $60 \ldots$ & -0321 & 5.42 & 0.056 & $\ldots$ & $111 \cdot 21$ & 161.53 & $\ldots$ & 58.17 & 1.0667 \\
\hline $70 \ldots$ & .0321 & 2783 & $0 \cdot 029$ & $\ldots$ & $99 \cdot 47$ & 178.23 & $\cdots$ & 66.43 & .0470 \\
\hline $80 \ldots$ & .0322 & $1 \cdot 740$ & 0.019 & $\ldots$ & $93 \cdot 06$ & 18294 & $\ldots$ & $60 \cdot 02$ & 0851 \\
\hline $100 \ldots$ & 0322 & 0.862 & $\ldots$ & $\ldots$ & $88 \cdot 20$ & $\ldots$ & $\ldots$ & $55 \cdot 16$ & .0325 \\
\hline $120 \ldots$ & 0323 & 0.450 & ... & $\ldots$ & $84 \cdot 40$ & $\cdots$ & $\cdots$ & $51 \cdot 36$ & .0641 \\
\hline $130 \ldots$ & 0322 & 0.237 & $\ldots$ & $\ldots$ & $77 \cdot 3$ & $\ldots$ & $\ldots$ & $44 \cdot 3$ & U045 \\
\hline
\end{tabular}


Wares of Magnetic Flux along Iron Wires.

TABLe IV.—Specimen A. T= $0216 \mathrm{q} \cdot \mathrm{p}$.

\begin{tabular}{|c|c|c|c|c|c|c|c|c|c|}
\hline \multicolumn{10}{|c|}{$\begin{array}{l}\mathrm{C}=\cdot 1776 \sin \omega t+\cdot 00728 \sin 3(\omega t-58 \cdot 3)+\cdot 00087 \sin 5(\omega t-30 \cdot 55) . \\
\mathrm{F}=f_{1} \sin (\omega t-\theta)+f_{3} \sin 3\left(\omega t-\theta-\beta_{3}\right)+f_{3} \sin 5\left(\omega t-\theta-\beta_{\bar{j}}\right) .\end{array}$} \\
\hline$x$. & T. & $f_{1}$. & $f_{3}$. & $f_{0}$. & $\theta$. & $\beta_{3}$. & $\beta_{i j}$. & $\theta_{x}-\theta_{0}$ & $\lambda_{i}$. \\
\hline 0. & 0216 & 3537 & $90 \cdot 6$ & $37 \cdot 7$ & $33 \cdot 75$ & $88 \cdot 57$ & $30 \cdot 68$ & 0 & \multirow{2}{*}{$\begin{array}{r}.0932 \\
.1014\end{array}$} \\
\hline $5 \ldots$ & -0216 & $2: 20$ & 963 & $25 \cdot 6$ & $48 \cdot 0 \pm$ & $85 \cdot 30$ & $25 \cdot 96$ & $14: 29$ & \\
\hline $15 \ldots$ & $\cdot 0216$ & $805 \cdot 5$ & $29 \cdot 3$ & 34 & $77 \cdot 30$ & $85 \cdot 64$ & 2253 & $43 \cdot 55$ & (1) \\
\hline $25 \ldots$ & .0216 & 251.9 & $4 \cdot 35$ & & $104 \cdot 37$ & $99 \cdot 48$ & & $70 \cdot 62$ & $\cdot 116$ \\
\hline $35 \ldots$ & .0217 & $62 \cdot 05$ & 0.67 & & $125 \cdot 69$ & 111.39 & & 91.94 & 1401 \\
\hline $45 \ldots$ & .0217 & 14.90 & $0 \cdot 20$ & & $132 \cdot 64$ & 124.01 & & $98 \cdot 89$ & 1426 \\
\hline $55 \ldots$ & .0217 & $5 \cdot 02$ & 0.06 & & $117 \cdot 00$ & $158 \cdot 35$ & & $83 \cdot 25$ & 08 \\
\hline $65 \ldots$ & 0217 & $2 \cdot 437$ & 0.038 & & 10353 & 16967 & & $69 \cdot 78$ & 0723 \\
\hline $80 \ldots$ & $\cdot 0217$ & $1 \cdot 236$ & 0.015 & & 9473 & 178.70 & & 60.98 & . 0453 \\
\hline $100 \ldots$ & $\cdot 0217$ & 0.597 & 0.009 & & $90 \div 59$ & $180 \cdot 57$ & & 56.84 & 64 \\
\hline $120 \ldots$ & 0216 & 0.336 & 0.006 & & $87 \cdot 13$ & $183 \cdot 43$ & & 5338 & 0286 \\
\hline $130 \ldots$ & .0217 & $0 \cdot 194$ & 0.005 & & $79 \cdot 47$ & 17973 & & $45 \cdot 72$ & .0547 \\
\hline
\end{tabular}

Table V.--Specimen A. $\quad \mathrm{T}=\infty$.

(Static Leak.)

\begin{tabular}{|c|c|c|c|c|c|c|c|}
\hline$x$. & C. & F. & $\lambda$. & $x$. & C. & F. & $\lambda$. \\
\hline $0 \ldots$ & 0751 & 3863 & & 40. & .0749 & $261 \cdot 3$ & \\
\hline 5 & 0750 & 2992 & .0511 & 50. & $\cdot 0752$ & $100 \cdot 8$ & $\cdot 0953$ \\
\hline $10 \ldots$ & $\cdot 0752$ & 2254 & 0566 & 60. & .0748 & $38 \cdot 7$ & .0955 \\
\hline $20 \ldots$ & $\cdot 0751$ & 1237 & .0600 & $80 .$. & .0750 & $7 \cdot 44$ & 0825 \\
\hline $30 \ldots$ & $\cdot 0751$ & $609 \cdot 4$ & .0708 & 100. & .0750 & $2 \cdot 60$ & 0525 \\
\hline 40 & 0749 & $261 \cdot 3$ & 0847 & 110. & 0750 & 1.49 & .0557 \\
\hline
\end{tabular}

6. In order to exhibit graphically some of the more striking results contained in the preceding tables, the curves in figs. 1 and 2 have been plotted. In fig. 1 the abscissæ are distances $x$ from the origin or magnetizing solenoid and the ordinates of one set of curves are the natural logarithms of the amplitudes of the first harmonic of the flux at different distances, while the ordinates of the other set of curves are the retardations in phase of the first harmonic of the flux at different distances behind that of the initial flux where $x=0$.

It will be seen that the $\log f_{1}, x$, curves are far from being straight lines as Zenneck assumed for the basis of his theoretical work. This is still more clearly shown in fig. 2, 
442 Prof. Lyle and Mr. Baldwin on Propagation of

Fig. 1.

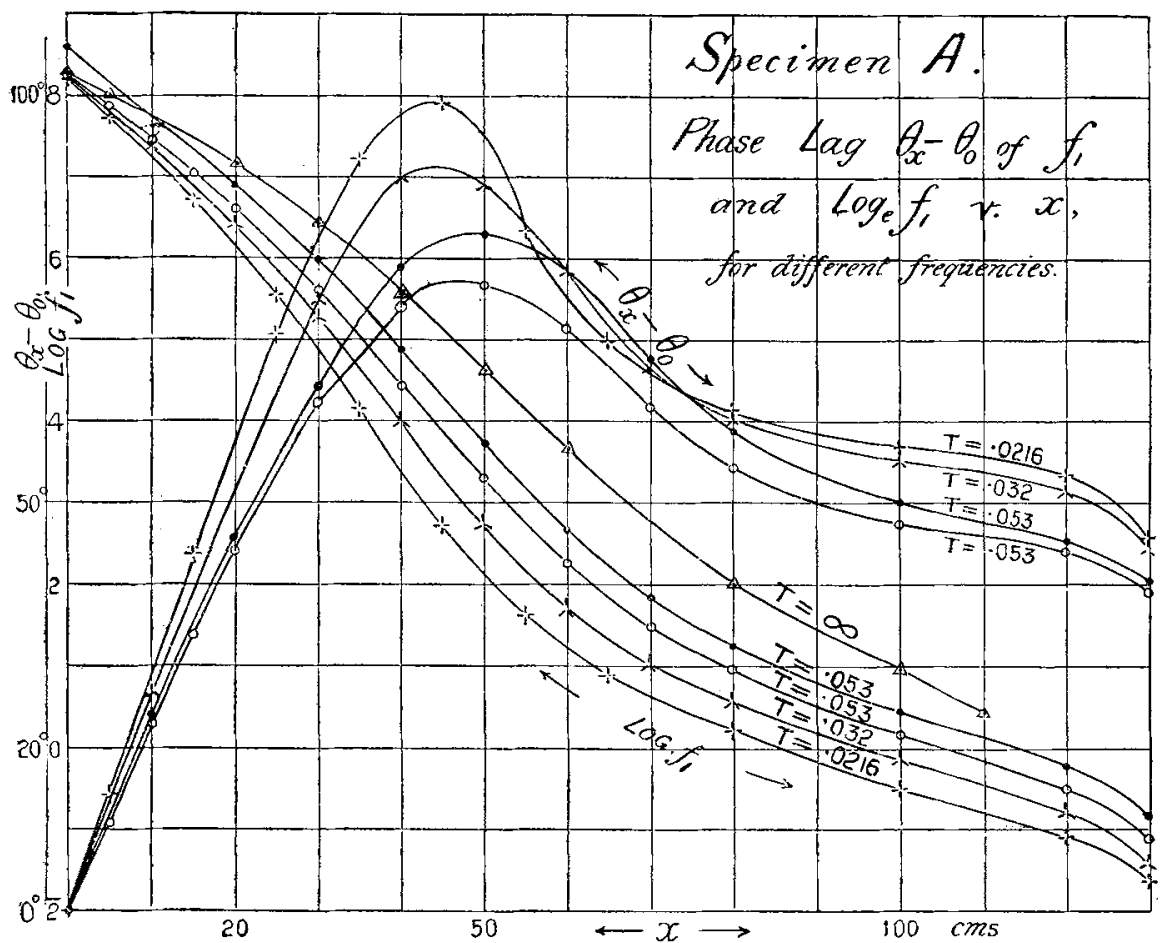

Fig. 2.

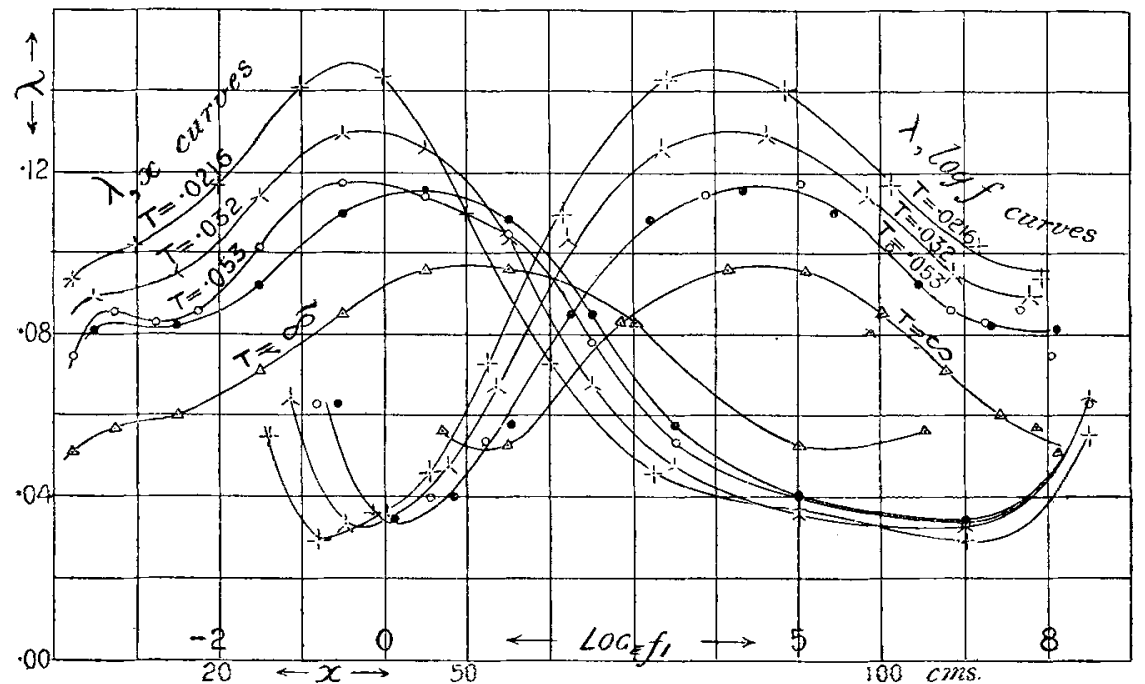


where the leakage coefficients $\lambda_{1}=-d\left(\log f_{1}\right) / d x$ are plotted against the distances from the origin at which they occur, as well as against $\log f_{1}$, the logarithm of the corresponding flux. Thus in all cases, including the statical, as we move away from the magnetizing coil, $\lambda_{1}$ first increases, attains a maximum, and then diminishes until near the end of the rod when it again increases. For the same initial flux both the points at which max. $\lambda_{1}$ occurs and the corresponding fluxes are different for different frequencies.

Figs. 1 and 2 show the effects of the end of the rod on the characteristies of the fluxes in its neighbourhood. Thus in fig. 1 the downward turn of the flux and phase curves lue to the end effect can be recognized $30 \mathrm{~cm}$. from the end of the rod, and the corresponding rise in the $\lambda$ curves in fig. 2 is very marked. The end effect always manifests itself in this way, and in very long rods this change in the direction of eurvature does not appear.

From the $\lambda_{1}, \log f_{1}$ curves in fig. 2 we see that for the same value of $f_{1}, \lambda_{1}$ increases with the frequency. In the same set it will be noticed that one curve can be drawn (q.p.) through the two series of points for $\lambda_{1}$ when $T=.053$ arising from two different initial fluxes. This would suggest that $\lambda_{1}$ is independent of $x$ and is a function of $f_{1}$ only. In the sequel it will be seen that $\lambda_{1}$ does depend on $x$ as well as on $f_{1}$, and the coincidence of the above two curves is due to the fact that with the initial values used (Tables I. and II.) there is never much difference between the abscisse at which equal fluxes occur in the two series.

Returning to fig. 1 we see how, for different frequencies, the phase of the first harmonic of the flux at any point $x$ lags behind that of the initial central flux at $x=0$.

Thus as the flux moves away from the magnetizing coil its phase is at first retarded at a fairly regular but diminishing rate for any one frequency, while for the higher frequencies the rate of retardation $d \dot{\theta} / d x$ is higher. Tlo this part of the phenomenon the observations of Oberbeck, Zenneck, and Perkins have been limited, and following them we would deduce (see $\$ 1$ ) from our results the following mean values for the "velocity of magnetization" over the first $30 \mathrm{cms}$. of the rod in question :-

$$
\begin{aligned}
& 3380 \mathrm{~cm} . / \mathrm{sec} \text {. when } \mathrm{T}=\cdot 053 \mathrm{sec} . \\
& 4790 \mathrm{~cm} / \mathrm{sec} . \quad \mathrm{T}=\cdot 032, \\
& 6230 \mathrm{~cm} . / \mathrm{sec} . \quad \mathrm{T}=0216,
\end{aligned}
$$

Continuing along the rod, however, we see that the spacerate of retardation $(d \theta / d x)$ of the phase becomes zero, and 


\section{Prof. Lyle and Mr. Baldwin on Propagation of}

the retardation itself a maximum at distances between 40 and $50 \mathrm{cms}$. from the starting-point, depending upon frequency and initial flux. After this the retardation diminishes, that is, the phase of the flux advances for the remainder of the length of the rod, and near the end the rate of advance $(-d \theta / d x)$ is greatly increased, this latter being due to the end effect.

From this it would seem that the deduction by Oberbeck and others of a "velocity of magnetization" from the rate of retardation $(d \theta / d x)$ of the phase of the flux close to the source by means of the formula

$$
v=\frac{2 \pi}{\mathrm{T} \frac{d \theta}{d x}}
$$

can hardly be legitimate.

For if so, we should have to allow that the "velocity" is infinite where the phase is stationary and $d \theta / d x=0$, and negative beyond this point, where the phase advances and $d \theta / d x$ is negative.

It is interesting to note that the points at which maximum phase retardation and maximum leakage coefficient occur are always situated very near each other.

7. It was thought that perhaps for the same frequency the phenomena at points in the rod beyond $x$ might depend in great part only on the flax at $x$; and if that were so, by making the initial flux as small as that at which maximum retardation occurred in any one of the preceding series, we should get an advance of phase right from the start at the magnetizing coil. To test this a rod of $\frac{1}{4}$ in. Lowmoor iron 12 it. long, taken from the same stock as specimen A, was used *.

The phase of the flux-wave at any point was taken as given directly by the divided-circle readings of the wavetracer when the ordinate was zero, and the amplitude was obtained by applying the proper factor to the maximum ordinate of the same flux-wave. This was sufficiently accurate for the purpose in hand. The results obtained are exhibited graphically in figs. 3,4 , and 5 . The initial values of the fluxes used were $69,163,288,687,1732,2994$, and 4100 , while the period was $\cdot 052$ sec. (q.p.) in all cases. In fig. 3 the logarithms (nat.) of the fluxes are plotted as ordinates against the corresponding distances from the origin as abscissa, the points pertaining to any one initial flux being

* When we thought of this, test specimen A had been cut up for the purpose of investigating change of length. 
Waves of Magnetic Flua: along Iron Wires.

Fig. 3.

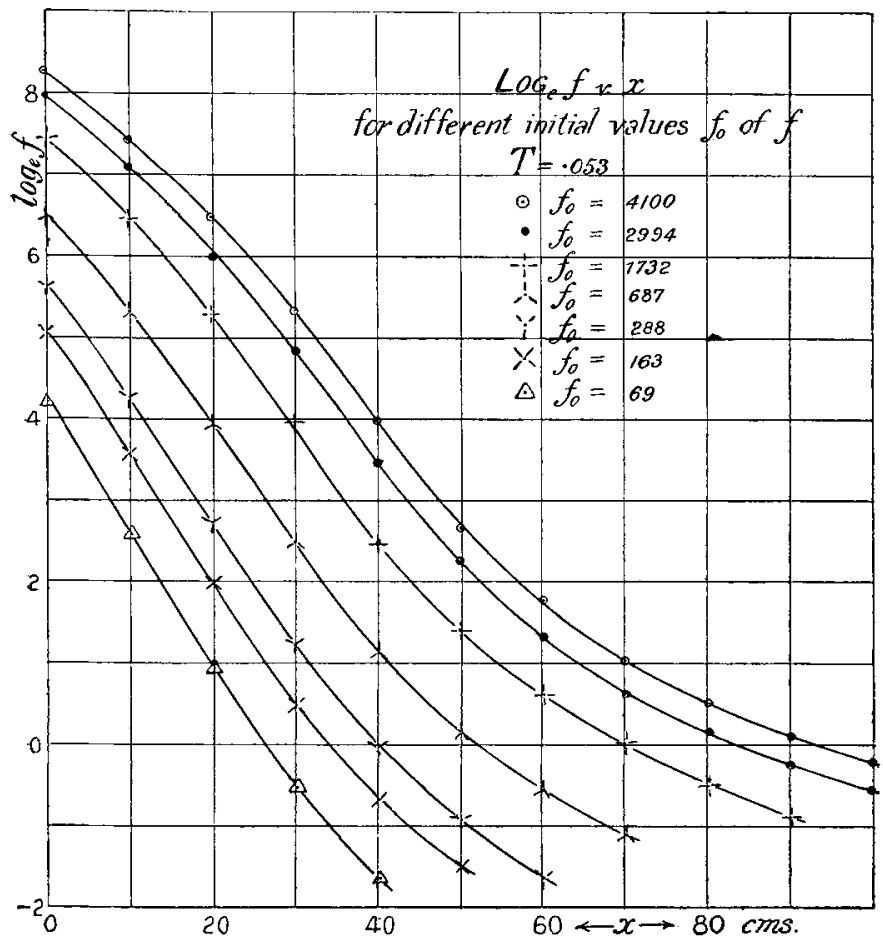

Fig. 4.

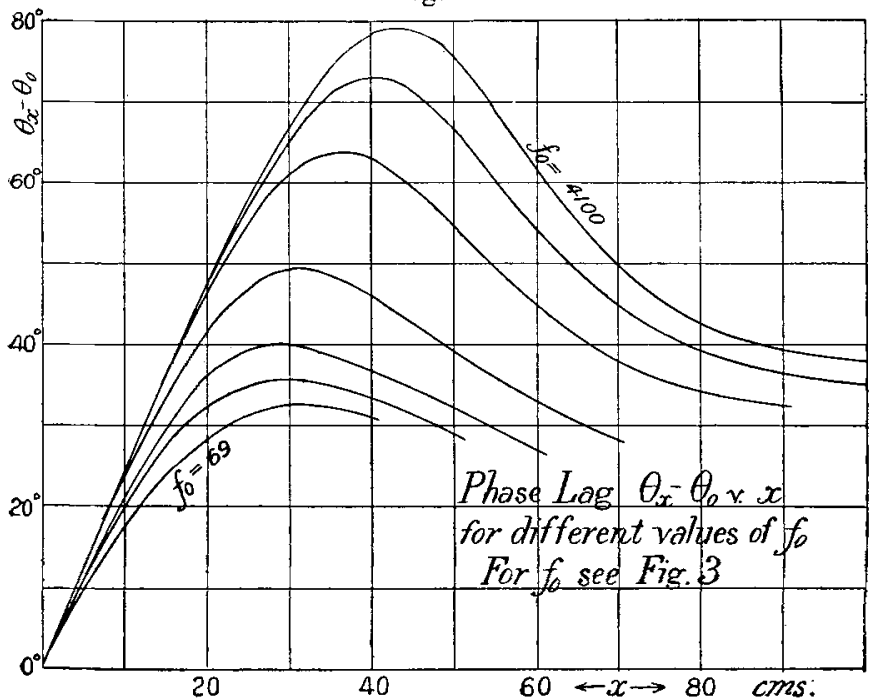




\section{Prof. Lyle and Mr. Baldwin on Propagation of}

joined (as also in figs. 4 and 5) by a continuous curve. In fig. 4 against the same abscisse are plotted the retardation in phase of the flux at any point behind that of the initial central flux; while in fig. 5 the leakage coefficients at different points in the several series are plotted as ordinates against the logarithms of their corresponding fluxes.

Fig. 5.

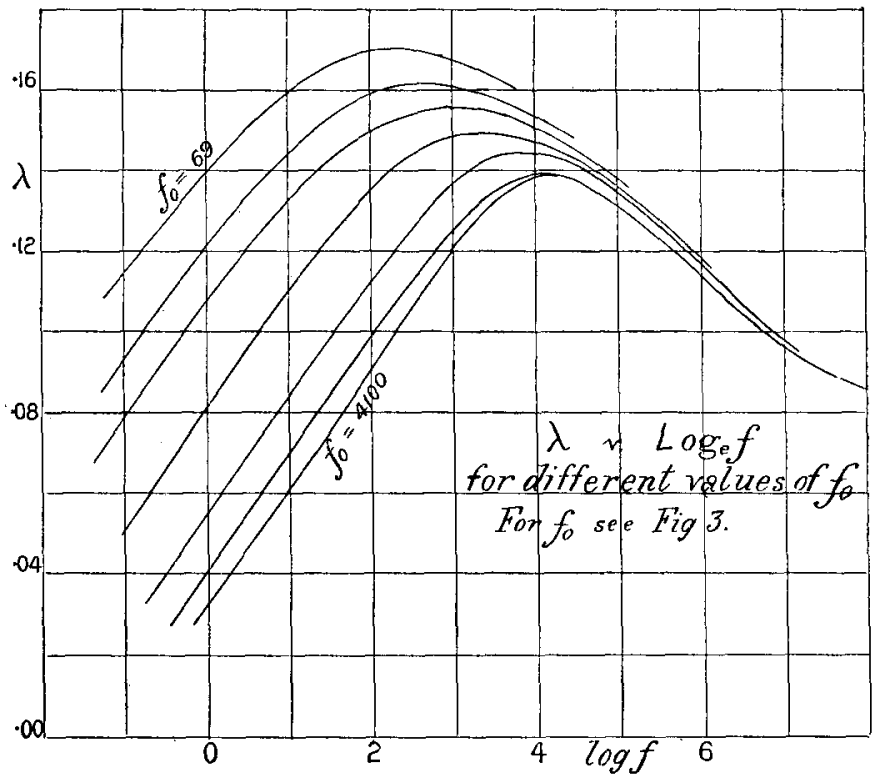

It will be seen that in all cases over the wide range of initial fluxes used, the general nature of the phenomena is the same as that exhibited by figs. 1 and 2 and detailed in Tables I.-IV. Always as the flux moves away from the origin its phase is at first retarded, the retardation attains a maximum, and then the phase advances and keeps advancing (as the rod is long) until the flux is completely dissipated. The leakage coefficient also always begins by increasing, attains a maximum and then diminishes; and we found in this case as in all others that the points on the rod at which maximum retardation and maximum leakage coefficient occurred were practically coincident. A glance at figs. 4 and 5 will show the effect of change of initial flux in the same specimen at the same frequency on the retardations of phase and the leakage coefficients. Thus increase of initial flux increases the maximum retardation, diminishes the 
maximum leakage coefficient, and increases the distance from the origin at which these two maxima concur.

As a result of this series of experiments it is plain that what may bappen at any one point of the rod, both as regards rate of retardation (or of advance as the ease may be) of phase and leakage depends both on the position of the point and on the value of the resultant flux at the point, and if we followed previous investigators in computing a "velocity of magnetization" we should obtain different velocities for the same flux and frequency, provided the points for which the velocity is computed were at different distrnces from the magnetizing coil.

Fig. 6.

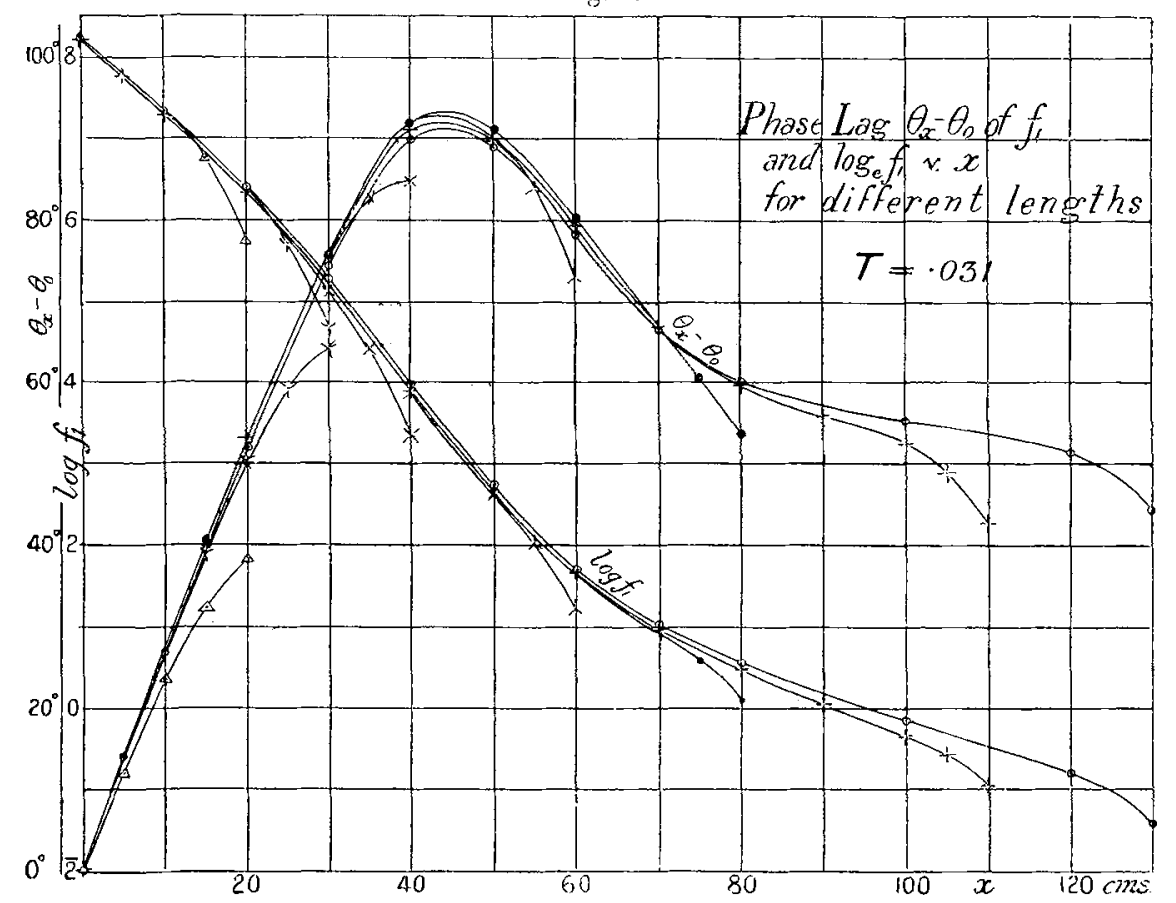

8. Specimen A was now reduced in length in successive steps by cutting each time equal portions off its two ends. For each length one series of observations was taken in which the initial flux and the frequency were approximately the same as in the series already given for the full length in Table III. The results obtained are given in detail in Tables VI. to XI., and the general effect of reduction in length on the lag in phase and on the logarithm of the amplitude of the first harmonic of the flux is exhibited in fig. 6 . 
448 Prof. Lyle and Mr. Baldwin on Propagation of

Table VI. - Specimen A reduced to $l=225 \mathrm{cms}$. $\mathrm{T}=\cdot 0316$.

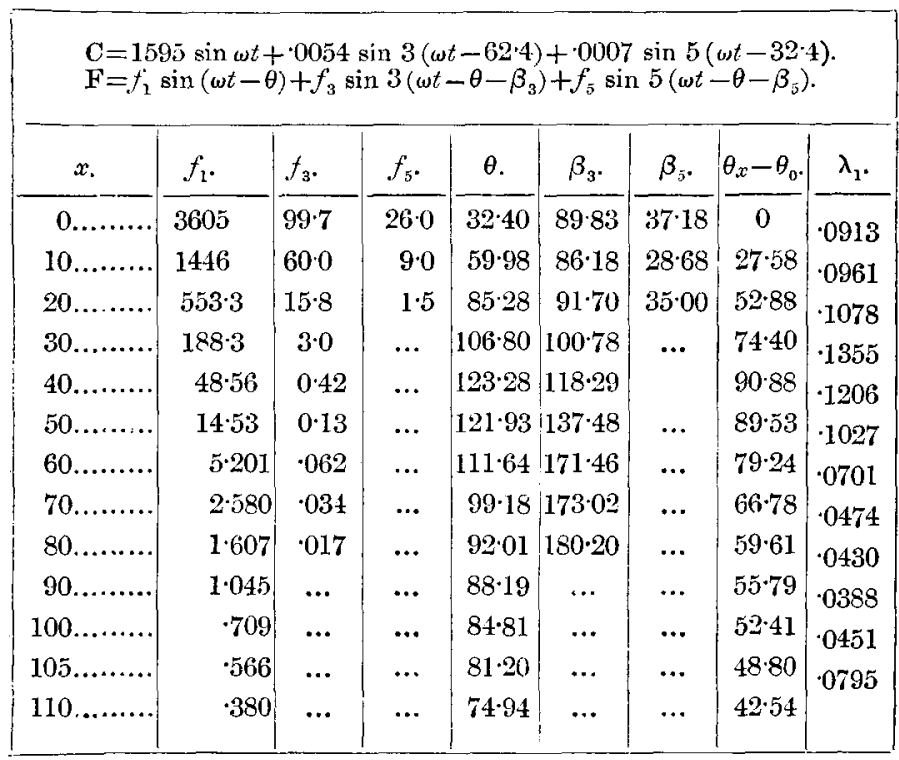

TABLE VII.-Specimen A reduced to $l=165 \mathrm{cms}$. $\mathrm{T}=\cdot 0309$.

\begin{tabular}{|c|c|c|c|c|c|c|c|c|}
\hline \multicolumn{9}{|c|}{$\mathrm{C}=\cdot 1683 \sin \omega t+\cdot 0063 \sin 3(\omega t-60)+\cdot 0011 \sin 5(\omega t-33)}$. \\
\hline$x$. & $f_{2}$. & $f_{3}$. & $f_{5}$. & 9. & $\beta_{3}$. & $\beta_{\bar{j}}$ & $\theta_{x}-\theta_{0}$ & $\lambda_{1}$ \\
\hline 0. & 3744 & $85 \cdot 5$ & $18 \cdot 1$ & $\overline{31 \cdot 23}$ & $87 \cdot 9$ & $31 \cdot 37$ & 0 & .090 \\
\hline $5 \ldots$ & 2378 & $95 \cdot 9$ & $17 \cdot 7$ & $44 \cdot 70$ & 88.08 & $28 \cdot 94$ & $13 \cdot 47$ & $\cdot 092$ \\
\hline $15 \ldots$ & $945 \cdot 7$ & $37 \cdot 6$ & $4 \cdot 84$ & $71 \cdot 78$ & $89 \cdot 15$ & $33 \cdot 77$ & 40.55 & .1087 \\
\hline $30 \ldots$ & $185 \cdot 0$ & 1.9 & ... & $106 \cdot 68$ & $102 \cdot 12$ & $\ldots$ & $75 \cdot 45$ & .1332 \\
\hline $40 \ldots$ & $48 \cdot 84$ & $0 \cdot 57$ & ... & $123 \cdot 06$ & 11574 & $\ldots$ & 91.83 & $\cdot 122$ \\
\hline $50 \ldots$ & $14 \cdot 37$ & $0 \cdot 15$ & $\cdots$ & $122 \cdot 20$ & 141.90 & $\cdots$ & 90.97 & .1025 \\
\hline $60 \ldots$ & $5 \cdot 153$ & $\cdot 076$ & $\ldots$ & $111 \cdot 41$ & 165.4 & $\ldots$ & $80 \cdot 18$ & .0719 \\
\hline $70 \ldots$ & $2 \cdot 510$ & .028 & $\ldots$ & $97 \cdot 95$ & $173 \cdot 9$ & $\ldots$ & 66.72 & 0676 \\
\hline $75 \ldots$ & $1 \cdot 790$ & .021 & $\ldots$ & 91.85 & 181.0 & $\cdots$ & $60 \cdot 62$ & . 1145 \\
\hline $80 \ldots$ & $1 \cdot 010$ & $\cdot 011$ & $\ldots$ & 84.91 & $183 \cdot 0$ & $\ldots$ & 5368 & \\
\hline
\end{tabular}


Waves of Magnetic Fluc along Iron Wires.

TABLE VIII.-Specimen A reduced to $l=125 \mathrm{cms}$. $\mathrm{T}=\cdot 0305$.

\begin{tabular}{|c|c|c|c|c|c|c|c|c|}
\hline \multicolumn{9}{|c|}{$C=\cdot 1722 \sin \omega t+\cdot 0066 \sin 3(\omega t-57 \cdot 5)+0008 \sin 5(\omega t-27)}$. \\
\hline$x$. & $f_{1}$. & $f_{3}$. & $f_{5}$. & $\theta$. & $\beta_{3}$. & $\beta_{\overline{5}}$. & $\theta_{x}-\theta_{0}$ & $\lambda_{1}$. \\
\hline 0.. & 3787 & $89 \cdot 7$ & $20 \cdot 7$ & $32 \cdot 86$ & $90 \cdot 88$ & $29 \cdot 23$ & 0 & .0917 \\
\hline $10 \ldots$ & 1514 & $61 \cdot 4$ & $11 \cdot 6$ & $60 \cdot 17$ & $87 \cdot 42$ & $23 \cdot 57$ & $27 \cdot 31$ & .0969 \\
\hline $20 .$. & 5742 & $17 \cdot 3$ & $\ldots$ & $85 \div 23$ & $91 \cdot 36$ & $\cdots$ & $5 \cdot 37$ & $\cdot 115$ \\
\hline 30. & $180 \cdot 8$ & 29 & $\ldots$ & 108.09 & $103 \cdot 31$ & $\ldots$ & $75 \cdot 23$ & $\cdot 1360$ \\
\hline $40 \ldots$ & $46 \cdot 42$ & 061 & $\ldots$ & 12462 & $110 \cdot 18$ & $\ldots$ & $91 \cdot 76$ & .1238 \\
\hline 50. & 13.46 & $0 \cdot 13$ & $\ldots$ & 122771 & 1408 & $\cdots$ & $89 \cdot 85$ & .1212 \\
\hline $55 \ldots$. & $7 \cdot 34$ & 0.07 & $\ldots$ & 116.67 & 1526 & $\ldots$ & $83 \cdot 81$ & $\cdot 1596$ \\
\hline 60. & $3 \cdot 31$ & 0.04 & $\ldots$ & $105 \cdot 61$ & 163.5 & $\ldots$ & 7275 & \\
\hline
\end{tabular}

TABLE IX.--Specimen A reduced to $l=85 \mathrm{cms}$. $\mathrm{T}=\cdot 0294$.

\begin{tabular}{|c|c|c|c|c|c|c|c|c|}
\hline \multicolumn{9}{|c|}{$=\cdot 1711 \sin \omega t+\cdot 0065 \sin 3(\omega t-59 \cdot 8)+\cdot 0007 \sin 5(\omega t-31 \cdot 7)}$. \\
\hline$x$. & $f_{1}$. & $f_{3}$. & $f_{j}^{\prime}$. & $\theta$. & $\beta_{*}$. & $\beta_{\bar{\sigma}}$. & $\theta_{x}-\theta_{0}$ & $\lambda_{1}$. \\
\hline 0. & 3684 & 915 & $26 \cdot 8$ & 3260 & $91 \cdot 4$ & $30 \cdot 14$ & 0 & 91 \\
\hline $10 .$. & 1471 & $66 \cdot 6$ & $13 \cdot 6$ & $59 \cdot 91$ & $87 \cdot 31$ & $25 \cdot 79$ & $27: 31$ & 197 \\
\hline 20. & $555 \div 5$ & $15 \cdot 9$ & $\ldots$ & $85 \cdot 32$ & $92 \cdot 21$ & $\ldots$ & 5272 & 9 \\
\hline 30. & $165 \cdot 3$ & $2 \cdot 76$ & $\ldots$ & $107 \cdot 53$ & 99.57 & $\ldots$ & 74.93 & 19 \\
\hline 35. & $80 \cdot 62$ & $1 \cdot 00$ & $\ldots$ & 11506 & $100 \cdot 70$ & $\ldots$ & $82 \cdot 46$ & \\
\hline 40. & 2801 & 0.26 & $\ldots$ & $117 \cdot 12$ & 107.58 & $\ldots$ & $84 \div 52$ & \\
\hline
\end{tabular}

TABLE X.-Specimen A reduced to $l=65 \mathrm{cms}$. $\mathrm{T}=\cdot 0311$.

\begin{tabular}{|c|c|c|c|c|c|c|c|c|}
\hline \multicolumn{9}{|c|}{$\mathrm{C}=\cdot 1718 \sin \omega t+\cdot 0067 \sin 3(\omega t-58 \cdot 1)+\cdot 0008 \sin 5(\omega t-26)}$. \\
\hline$x$. & $f_{1}$. & $f_{3}$ & $\dot{t}_{5}$ & $\theta$. & $\beta_{3}$. & $\beta_{\overline{5}}$. & $\theta_{x}-\theta_{0}$ & $\lambda_{1}$. \\
\hline 0. & 3794 & $87 \cdot 6$ & 260 & $3 \approx 66$ & $89 \cdot 0$ & $31 \cdot 67$ & 0 & \\
\hline $10 \ldots$ & 1539 & 656 & $12 \cdot 1$ & $59 \cdot 72$ & $85 \cdot 97$ & 27.87 & $27 \cdot 06$ & 698 \\
\hline $15 \ldots$ & $970 \cdot 4$ & $35 \cdot 9$ & $5 \cdot 3$ & $71 \cdot 41$ & $88 \cdot 43$ & $25 \cdot 40$ & 38.75 & $\cdot 104$ \\
\hline $20 \ldots$ & $575 \cdot 1$ & $19 \cdot 42$ & 1.85 & $82 \cdot 82$ & 9276 & $\ldots$ & $50 \cdot 16$ & 30 \\
\hline $25 \ldots$ & $298 \cdot 0$ & $7 \cdot 71$ & $\ldots$ & 91.79 & $96: 36$ & $\ldots$ & $59 \cdot 13$ & .208 \\
\hline $30 \ldots$ & 1053 & $2 \cdot 38$ & $\ldots$ & 96.67 & 96.33 & $\ldots$ & 64.01 & \\
\hline
\end{tabular}

Phil. Mag. S. 6. Vol. 12. No. 71. Nov. 1906.2 G 
TABLE XI.-Specimen A reduced to $l=45 \mathrm{cms}$. $\mathrm{T}=\cdot() 311$.

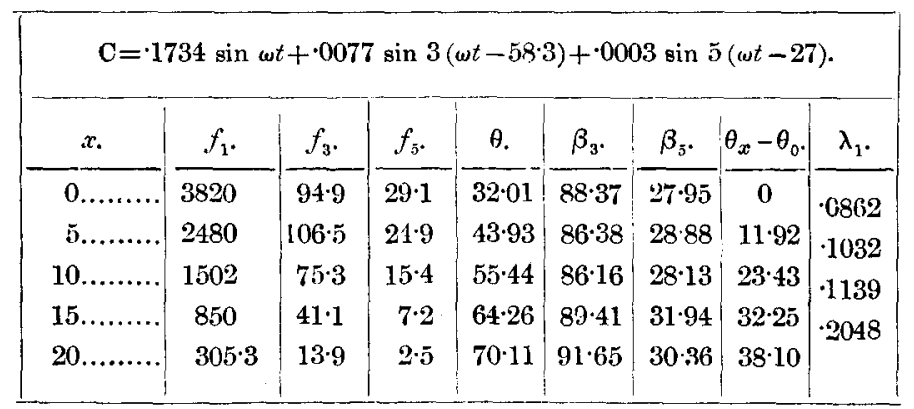

From the tables and from fig. 6 it will be seen that shortening the rod makes little perceptible difference either to the leakage of the flux or to its phase-lag until a point is reached at which the end effect begins to assert itself. Thus for the different lengths, flux-waves that are equal at the magnetizing coil are practically equal in all their characteristics after travelling equal distances along the rod, provided they have not reached to within $30 \mathrm{cms}$. or so from the ends.

9. The next specimen (B) tested was a rod of silver-steel of low permeability of the same section as specimen A. One frequency with one initial flux only was used, these being (q. p.) the same as in one of the series (Table III.) of experiments with specimen $A$, so that a direct comparison of the behaviour of the two materials could be readily made.

\section{Details of Specimen B.}

A straight cylindrical rod of silver-steel.

Length $=286^{\circ} 6 \mathrm{cms}$. Diameter $=\cdot 653 \mathrm{~cm}$.

Section $=\cdot 3351 \mathrm{~cm}^{2}$.

Magnetizing solenoid and search-coils the same as were used with specimen $A$.

Specific resistance $=1 \cdot 859 \times 10^{4}$.

Statical Permeability for different inductions.

\begin{tabular}{|r|r|r|r|r|r|r|r|r|r|r|}
\hline B $\ldots . .$. & 50 & 500 & 1000 & 2000 & 4000 & 6000 & 8000 & 10000 & 12500 & 15000 \\
\hline$\mu \ldots .$. & 73 & 96 & 122 & 170 & 248 & 298 & 316 & 290 & 222 & $\mathbf{1} 40$ \\
\hline
\end{tabular}


TABLE XII.--Specimen B, $\mathrm{T}=\cdot 0305$.

\begin{tabular}{|c|c|c|c|c|c|c|c|c|c|c|c|c|c|c|c|c|c|c|}
\hline \multicolumn{19}{|c|}{$\mathbf{C}=224 \sin \omega t ; \mathrm{F}=f_{1} \sin (\omega t-\theta)$} \\
\hline$x$ & 0 & 5 & 10 & 15 & 20 & 30 & 41 & & 60 & 80 & 100 & 11 & 10 & 120 & 130 & 14 & \begin{tabular}{l|l}
10 & 1
\end{tabular} & 145 \\
\hline$f_{\mathfrak{l}}$ & 3735 & 1855 & 700 & 236 & $80 \div 3$ & 166 & $5 \cdot$ & & $\cdot 34$ & 0.53 & 26 & & 190 & $\cdot 142$ & 106 & $6 \cdot 0$ & 71 & 053 \\
\hline & $28 \cdot 4$ & $35 \cdot 7$ & $47 \cdot 5 \mid$ & 537 & $54 \cdot 7$ & $47 \cdot 7$ & 42 & & $39 \cdot 0$ & $38 \cdot 6$ & 38 & & 85 & $38 \cdot 2$ & $39 \cdot$ & 57 & $\cdot 43$ & $7 \cdot 6$ \\
\hline$\theta_{x}-\theta_{0} \ldots$ & & $12 \cdot 3$ & $24 \cdot 1$ & $30 \cdot 3$ & $31 \cdot 3$ & $24 \cdot 3$ & 19 & & $5 \cdot 6$ & $15 * 2$ & 15 & 1 & $5 \cdot 1$ & $14: 8$ & $16 \cdot 1$ & & 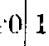 & $4 \cdot 2$ \\
\hline$\lambda_{2} \ldots \ldots$ & $\cdot 14$ & $40 \cdot 19$ & $95 \cdot 217$ & $7 \cdot 210$ & $6 \cdot 15^{\prime}$ & $57 \cdot 11$ & 14. & 069 & .047 & $\begin{array}{ll}7 \cdot 03 \\
\end{array}$ & & 33 & 030 & $\begin{array}{l:l}0 & 02\end{array}$ & & 40 & .058 & \\
\hline
\end{tabular}

Table XIII.-Static Leak. Specimen B. $T=\infty$.

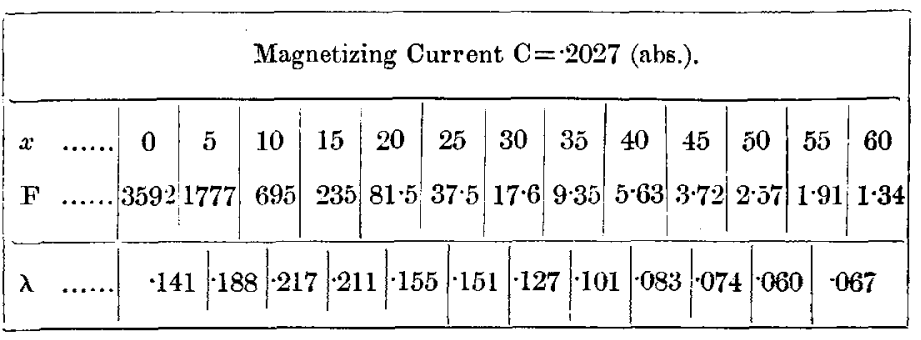

Tables XII. and XIII. give the results of the experiments with this specimen, the characteristics of the first harmonic of the flux only being given.

By comparing Tables III. and XII. one can see the difference in the behaviour of similar rods of iron and steel for the same initial flux and the same frequency. Fig. 7 illustrates the difference graphically. Thus, though near the origin the rate of retardation of phase $(d \theta / d x)$ is nearly the same for both specimens (hence giving nearly equal tictitious velocities of magnetization), yet in the steel rod the retardation attains its maximum at less than half the distance from the origin at which it attains its maximum in the iron rod, and the maximum valne in the latter rod is about three times what it is in the former. Again, for the steel rod the leakage coefficients are at first very much larger than for the iron one (see fig. 8), either at equal distances from the origin, or for equal fluxes; but when very low values of the flux have been arrived at, the leakage coefficients are quite as small in the steel as in the iron. 
It will be noticed (see Table XII.) that in this specimen also the positions of max. retardation and max. leakage coefficient very nearly if not quite coincide.

10. The cause of the difference in the leakage-curves for the two rods is naturally to be looked for in their very different permeability-curves. Of the flux $\mathrm{F}$ which crosses any section

Fig. 7 .

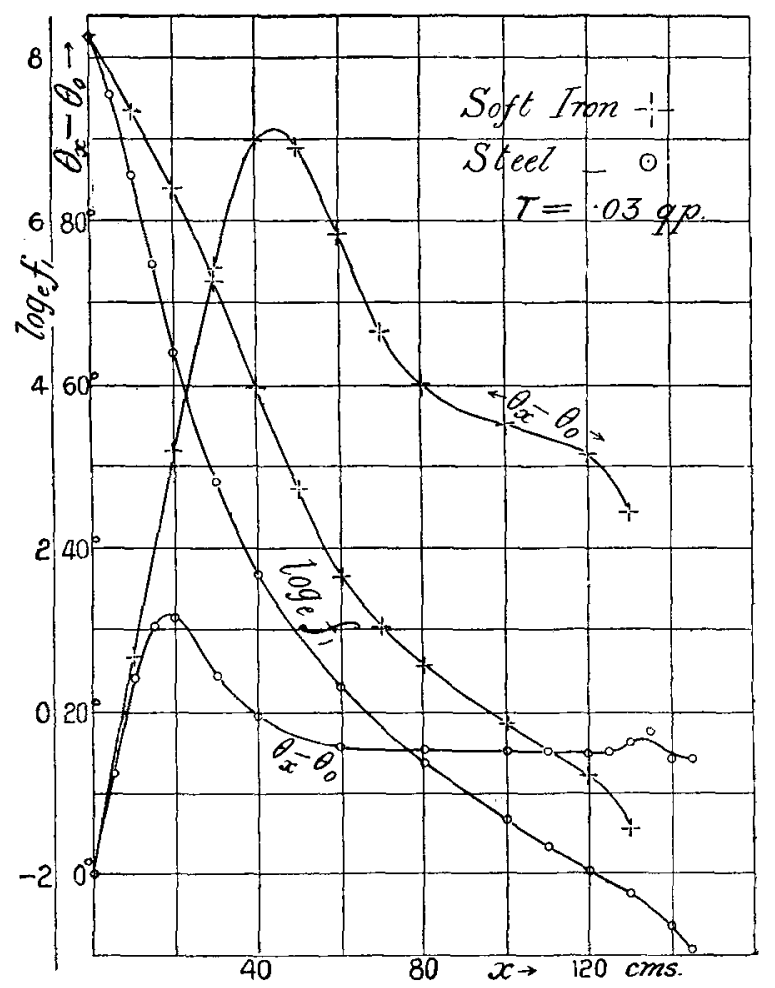

of the rod, $-d \mathrm{~F}$ leaks out in the next elementary length $d x$, and $\mathrm{F}+d \mathrm{~F}$ continues in the rod, and the ratio of $-d \mathrm{~F}$ to $\mathrm{F}+d \mathrm{~F}($ i.e. $-d \mathrm{~F} / \mathrm{F}$ in the limit) will, when the magnetizing force is constant, be equal to the inverse ratio of the reluctances of the two corresponding paths. When the magnetizing force is periodic, the phenomenon is further complicated by the eddy currents set up in the rod, giving rise to back magnetomotive forces. If, for two different rods, the reluctances of two elementary leakage-paths (air) were equal, then 
$-d \mathrm{~F} / \mathrm{F}$ for the corresponding elements (and therefore $\lambda$, as $\lambda d x=-d \mathrm{~F} / \mathrm{F}$ ) would be proportional to the reluctances of the second paths (partly in the materials), and thus would be greater for the less permeable substance. However, as $\lambda$ depends on the ratio of two reluctances, it is quite conceivable that this ratio might be smaller for points on a rod of low permeability than for the corresponding point on a rod of higher permeability. (See fig. 8.)

Fig. 8.

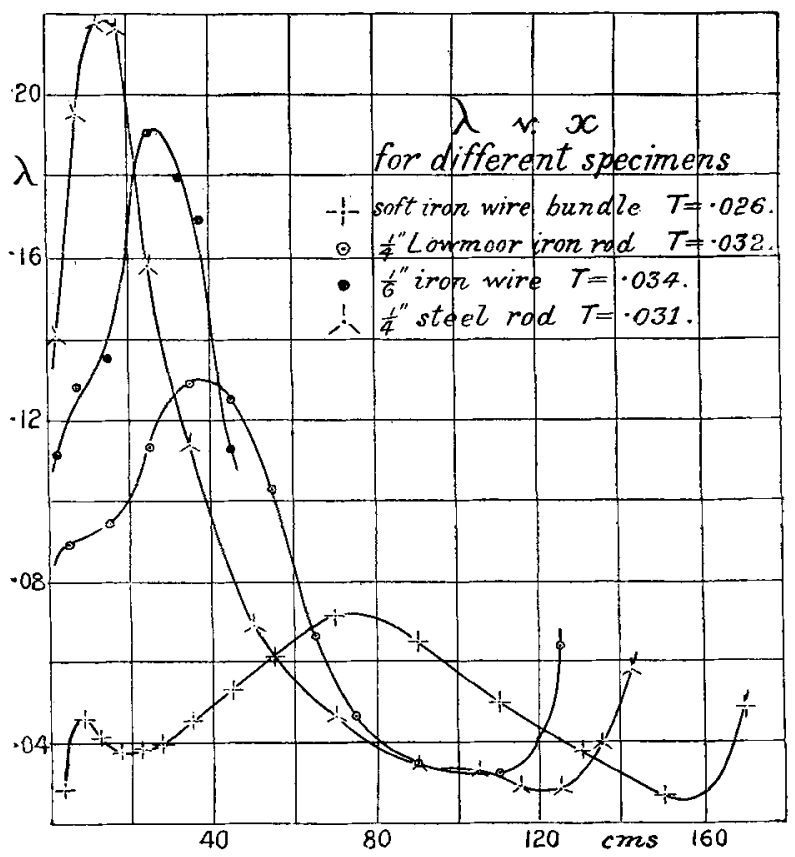

Again, $\lambda$ at a point near the end of a finite rod for a given initial flux and frequency must be greater than $\lambda$ for a point equidistant from the magnetizing solenoid in an infinite rod of the same material and cross-section ; for the reluctances of the elementary leakage paths through the air will be equal, while the second path for the infinite rod must have a lower reluctance than that for the finite rod, seeing that iron in the former takes the place of some of the circuit, which is air for the latter. Thus the "end effect" on the leakage coefficient is to make its value larger. 


\section{Prof. Lyle and Mr. Baldwin on Propagation of}

11. C, the next specimen tested, was a long thick iron wire. Three series of experiments were made with it for three different frequencies and approximately the same initial flux.

\section{Details of Specimen C.}

A straight iron wire.

Length $=324 \mathrm{cms}$. Diameter $=\cdot 398 \mathrm{~cm}$.

Section $=0 \cdot 1244 \mathrm{~cm}^{2}$.

Specitic resistance $=1.006 \times 10^{4}$.

Magnetizing solenoid and search-coils the same as were used with specimen $A$.

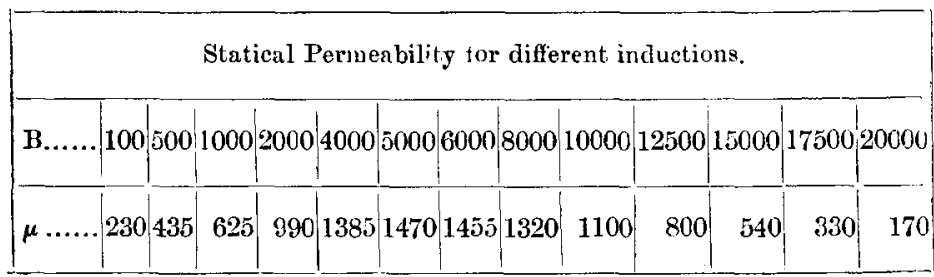

In Tables XIV., XV., and XVI. are given the analysed results of the alternating flux experiments with this specimen, and in Table XVII. the results with the continuous flux.

TABLE XIV.-Specimen C. $\mathrm{T}=\cdot 0545$.

\begin{tabular}{|c|c|c|c|c|c|c|c|c|}
\hline \multicolumn{9}{|c|}{$\begin{array}{l}\mathbf{C}=\cdot 1742 \sin \omega t-0091 \sin 3(\omega t+1 \cdot 15)-\cdot 0011 \sin 5(\omega t-26 \cdot 1) \\
\mathrm{F}=f_{1} \sin (\omega t-\theta)+f_{3}^{\prime} \sin 3\left(\omega t-\theta-\beta_{3}\right)+f_{5} \sin 5\left(\omega t-\theta-\beta_{5}\right) .\end{array}$} \\
\hline$x$ & $f_{1}$ & $f_{3}$. & $f_{5}$ & $\theta$. & $\beta_{3}$. & $\beta_{5}$. & $\theta_{x}-\theta_{0}$ & $\lambda_{1}$. \\
\hline $0 \ldots \ldots$. & 2360 & $\overline{189 \cdot 0}$ & $41 \cdot 8$ & 22.05 & $3 \cdot 28$ & $45 \cdot 08$ & 0 & .0898 \\
\hline $5 \ldots \ldots$ & 1505 & $100 \cdot 9$ & $19 \cdot 0$ & $34 \cdot 50$ & $-6 \cdot 10$ & 45.07 & $12 \cdot 45$ & .1150 \\
\hline 10 & 847.5 & $59 \cdot 8$ & $10 \cdot 2$ & $47 \cdot 18$ & $-11 \cdot 81$ & $40 \cdot 74$ & $25 \cdot 13$ & $\cdot 1245$ \\
\hline 20 & 244 & 165 & $1 \cdot 6$ & $69 \cdot 82$ & $-14 \cdot 88$ & $48 \cdot 26$ & 47.75 & $\cdot 1760$ \\
\hline 30 & $42 \cdot 0$ & 1.9 & 03 & 8397 & -8.82 & $63 \cdot 34$ & 61.92 & .1774 \\
\hline 35 & $17 \cdot 3$ & 0.44 & 0.12 & 7909 & -1.85 & $68 \cdot 62$ & 57.04 & .1800 \\
\hline 40 & 7.02 & 0.09 & 0.05 & $71 \cdot 05$ & -7.73 & 7906 & $49 \cdot 00$ & 1207 \\
\hline $50 \ldots \ldots \ldots$ & $2 \cdot 10$ & 0.09 & $\ldots$ & $53 \cdot 54$ & $-11 \cdot 45$ & $\ldots$ & $31 \cdot 49$ & 0750 \\
\hline $60 \ldots \ldots$. & 0.98 & 0.06 & $\ldots$ & $46 \cdot 23$ & -5.57 & $\ldots$ & 24.1.7 & $0 \$ 10$ \\
\hline $70 \ldots \ldots$. & 0.59 & 0.05 & $\ldots$ & $39 \cdot 72$ & +1.90 & $\ldots$ & 1766 & \\
\hline
\end{tabular}


Waves of Magnetic Flux along Iron Wires.

Table XV.—Specimen C. $\mathrm{T}=\cdot 034$.

\begin{tabular}{|c|c|c|c|c|c|c|c|c|c|}
\hline \multicolumn{10}{|c|}{$\begin{array}{l}\mathrm{O}=\cdot 1737 \sin \omega t-\cdot 0096 \sin 3(\omega t-0 \cdot 24) \\
\mathbf{F}=f_{1} \sin (\omega t-\theta)+f_{3} \sin 3\left(\omega t-\theta-\beta_{3}\right)+f_{5} \sin 5\left(\omega t-\theta-\beta_{5}\right) .\end{array}$} \\
\hline & $x$. & $f_{1}$. & $f_{3}$. & $f_{5}$ & $\theta$. & $\beta_{3}$. & $\beta_{5}$. & $\theta_{x}-\theta_{0}$ & $\lambda_{1}$ \\
\hline 0 & ...... & 2220 & 87 & 34 & $27 \cdot 00$ & $-1 \cdot 33$ & $42: 56$ & 0 & $\cdot 1034$ \\
\hline $\mathbf{5}$ & & 1326 & 54 & 15 & $40.5 \check{5}$ & $-16 \cdot 36$ & $36 \cdot 21$ & 13.55 & .1272 \\
\hline 10 & ... & 702 & 36 & 7 & 5607 & $-20 \cdot 51$ & $36 \cdot 24$ & 29.07 & -1351 \\
\hline 20. & & $181 \cdot 7$ & 8.9 & $\ldots$ & 81.94 & $-18 \cdot 71$ & $\ldots$ & 54.94 & -1904 \\
\hline 30 . & & $27 \cdot 1$ & $0 \cdot 6$ & $\ldots$ & 96.95 & $-6 \cdot 62$ & $\cdots$ & $69 \cdot 95$ & $\cdot 1792$ \\
\hline 35 & & $11 \cdot 05$ & 0.07 & $\ldots$ & 88.46 & +16.98 & $\ldots$ & $61 \cdot 46$ & -1687 \\
\hline 40. & $\cdots$ & $4 \cdot 75$ & $0 \cdot 04$ & $\ldots$ & $77 \cdot 14$ & 66.04 & $\ldots$ & $50 \cdot 14$ & -1123 \\
\hline 50 & .... & $1 \cdot 55$ & $0 \cdot 04$ & $\cdots$ & 56.41 & $130 \cdot 2$ & $\cdots$ & $29 \cdot 41$ & \\
\hline
\end{tabular}

TABLE XVI.-Specimen C. $\mathrm{T}=\cdot 0234$.

\begin{tabular}{|c|c|c|c|c|c|c|c|c|c|}
\hline \multicolumn{10}{|c|}{$\begin{array}{l}\mathrm{C}=\cdot 1803 \sin \omega t-0072 \sin 3(\omega t+3 \cdot 32)+\cdot 0016 \sin 5(\omega t-6 \cdot 6) . \\
\mathrm{F}=f_{1} \sin (\omega t-\theta)+f_{3} \sin 3\left(\omega t-\theta-\beta_{3}\right)+f_{3} \sin 5\left(\omega t-\theta-\beta_{5}\right) .\end{array}$} \\
\hline & & $f_{1}$. & $f_{3}$ & $f_{5}$. & $\theta$. & $\beta_{3}$. & $\boldsymbol{\beta}_{5}$. & $\theta_{x}-\theta_{0}$ & $\lambda_{1}$ \\
\hline 0 & & 2115 & 75 & 28 & $30 \cdot 40$ & $-15 \cdot 46$ & 4270 & 0 & .1148 \\
\hline 5 & & 1192 & 59 & 16 & $45 \cdot 26$ & $-26 \cdot 67$ & $35 \cdot 00$ & $14 \cdot 86$ & $\cdot 1388$ \\
\hline 10 & & $595 \cdot 4$ & $29 \cdot 4$ & $6 \cdot 4$ & $62 \cdot 07$ & $-27 \cdot 00$ & 30.72 & $31 \cdot 67$ & $\cdot 1515$ \\
\hline 20 & & $130 \cdot 9$ & $4 \cdot 9$ & $\ldots$ & $91 \cdot 13$ & $-22 \cdot 21$ & $\ldots$ & $60 \cdot 73$ & $\cdot 2053$ \\
\hline 30 & & $16 \cdot 80$ & $0 \cdot 18$ & $\ldots$ & $104 \cdot 61$ & +508 & $\ldots$ & $74 \cdot 21$ & $\cdot 1763$ \\
\hline 35 & & 6.96 & $0 \cdot 10$ & ... & 90.53 & $49 \cdot 92$ & $\ldots$ & $60 \cdot 13$ & ·1494 \\
\hline 40 & & $3 \cdot 30$ & 0.07 & $\ldots$ & 76.41 & 66.49 & ... & $46 \cdot 01$ & $\cdot 1057$ \\
\hline 50 & & 114 & $0 \cdot 06$ & $\ldots$ & $58 \cdot 76$ & $94: 31$ & $\ldots$ & $28 \cdot 36$ & \\
\hline
\end{tabular}

TAble XVII.-Static Leak. Specimen C. T $=\infty$.

\begin{tabular}{|c|c|c|c|c|c|c|c|c|c|c|c|c|c|c|}
\hline \multicolumn{15}{|c|}{ Magnetizing Current, $\mathrm{C}=\cdot 1844$ (abs.). } \\
\hline$x \ldots \ldots . .$. & 0 & 5 & 10 & 15 & 20 & & 25 & 30 & 35 & 40 & $0 \mid \leq$ & 45 & 50 & 55 \\
\hline $\mathbf{F}$ & 2220 & 1476 & 919 & 559 & $9 \mid 318$ & & 62 & $77 \cdot 5$ & $31 \cdot 6$ & 612 & & $\left.5 \cdot 83\right|^{3}$ & $3 \cdot 01 \mid$ & 1.98 \\
\hline$\lambda \quad \ldots \ldots$ & $\cdot 082$ & 09 & $95 \cdot 09$ & $99 \cdot 1$ & 123 & $\cdot 135$ & .147 & $7 \mid \cdot 17$ & $79 \cdot 1$ & 183 & 154 & $4 \cdot 132$ & $32 \mid \cdot 0$ & 084 \\
\hline
\end{tabular}




\section{6}

\section{Prof. Lyle and Mr. Baldwin on Propagation of}

In the series of experiments with this specimen the flux density at the centre was much higher $(18,000$ instead of $10,000)$ than in the corresponding series with specimen A. The series with rod A, given in Table II., in which the induction at the centre was about 15,000 , will, however, afford a comparison under more nearly similar conditions, and we can see that the leakage coefficients for the thinner rod are considerably higher than for the other (see fig. 8). On account of the smaller sectional area and greater leakage, observations were of necessity limited to a shorter range than for the other specimens, but within this range the phenomena observed and recorded in the preceding tables are similar in all respects to those observed with the previous specimens. In particular the leakage coefficient again attains a maximum value at or very near to the position for maximum phase-lag.

It is also worthy of notice that the value of $d \theta / d x$ near the origin is larger than for specimen $A$, the mean values of the fictitious "velocity of magnetization" for the first $20 \mathrm{cms}$. (a range within which in this specimen $d \theta / d i c$ is fairly uniform) being

$$
\begin{aligned}
& 2750 \mathrm{cms} . / \mathrm{sec} . \text { when } \mathrm{T}=\cdot 0545, \\
& 3850 \mathrm{cms} . / \mathrm{sec} . \quad \Rightarrow \mathrm{T}=\cdot 034, \\
& 5060 \mathrm{cms} . / \mathrm{sec} . \quad \quad \mathrm{T}=\cdot 0234,
\end{aligned}
$$

values considerably smaller than those for specimen A. 'This

Fig. 9.

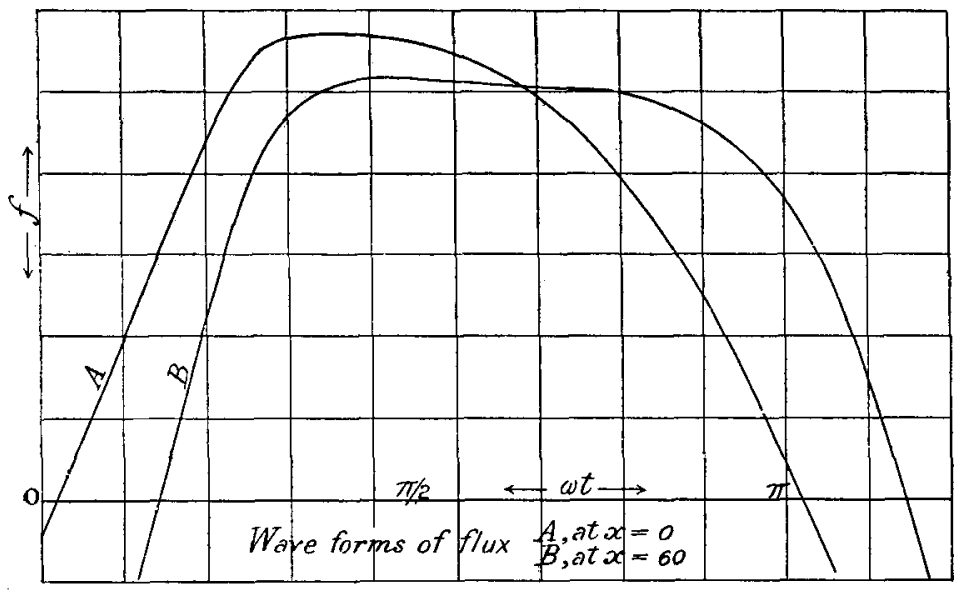

agrees with the results of some experiments that will be described further on, which show that reducing the diameter 
of the specimen, other things being equal, increases the space rate of retardation of the flux near the origin.

There might seem to be a diserepancy when the values of $f_{1}$ for $x=0$ in Tables XIV., XV., XVI. relative to the first harmonics of their magnetizing currents are compared with the value of $F_{0}$ in Table XVII. relative to the continuous current producing $\mathrm{F}_{0}$. The iron seems to be quite as permeable under alternating magnetization as under continuous. This apparent discrepancy will disappear (and this remark will apply to the other specimens) when it is remembered (a) that the form of the current wave is peaked and its max. ordinate is greater than the amplitude of its first harmonic, (b) that the form of the flux-wave is flat and its max. ordinate is less than the amplitude of its first harmonic.

Thus the max. values of $\mathrm{C}$ and $\mathrm{F}_{0}$ for the different values of $\mathrm{T}$ in the above are as follows :-

\begin{tabular}{|c|c|c|c|c|}
\hline $\mathrm{T} \ldots \ldots \ldots . . .$. & $\infty$ & 0545 & $\cdot 034$ & 0234 \\
\hline $\mathbf{C}_{\max . \ldots . . .}$ & $\cdot 1844$ & $\cdot 1854$ & $\cdot 1850$ & $\cdot 1866$ \\
$F_{\max . \ldots . . . .}$ & 2220 & 2160 & 2100 & 2034 \\
\hline
\end{tabular}

12. Eddy currents must play an important part in the phenomena under consideration, and their effects in this connexion may, in a general way, be explained as follows. If the vector $\mathrm{OF}$ (fig. 10) represent the resultant flux down

Fig. ]0.

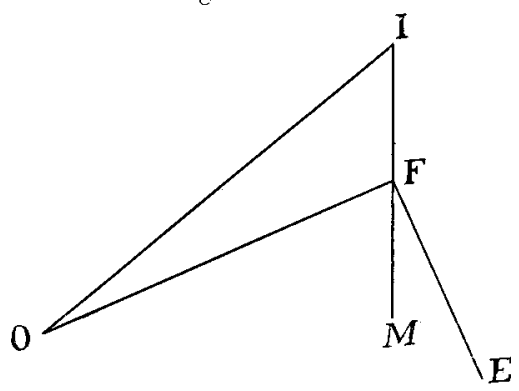

any cylindrical portion of a rod, the E.M.F. produced by its variation in a circuit in the rod round the outside of this cylinder, being in quadrature with $O F$ and behind it in phase, may be represented by a vector $\mathrm{FE}$ where the angle $\mathrm{OFE}$ is a right angle. This E.M.F. generates an eddy 


\section{8}

Prof. Lyle and Mr. Baldwin on Propagation of

current which generates a flux down the cylinder that lags behind $\mathrm{FE}$ in phase, and hence may be represented by some such vector as $F M$ or IF, where IF $=F M$. Hence the vector OI will represent in amplitude and phase the flux that would have passed down the cylinder if the eddy current had not been present. Thus we see that the effects of eddy currents at any point of one of our specimens are $(a)$ an increase in the phase retardation, i. e. in $\theta_{x}-\theta_{0} ;(b)$ a diminution in the amplitude of the Hux there, which manifests itself as an increase in $\lambda$ the leakage coefficient.

A further set of experiments was undertaken in which these eddy-current effects were much reduced by replacing the solid rod by a cylindrical bundle of soft iron wires, called specimen $\mathrm{D}$, of which the details are as follows:-

\section{Details of Specimen $D$.}

A cylindrical bundle of soft iron wires.

Number of wires $=185$.

Length of each wire $=368 \mathrm{cms}$.

Diameter,$\quad=\cdot 0791 \mathrm{~cm}$.

Area of iron section of specimen $=\cdot 909 \mathrm{~cm}^{2}$

Diameter of bundle $=1.5 \mathrm{~cm}$.

Specific resistance of iron $=1.366 \times 10^{4}$.

No. of turns on magnetizing coil $=366$.

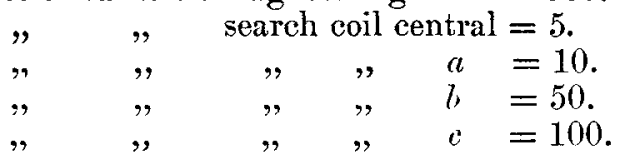

\begin{tabular}{|c|c|c|c|c|c|c|c|c|c|}
\hline \multicolumn{10}{|c|}{ Statical Permeability for different inductions. } \\
\hline $\mathbf{B}$ & 100 & 1000 & 2000 & 4000 & 5000 & 6000 & 8000 & 10000 & 12000 \\
\hline$\mu$ & 202 & 475 & 750 & 1140 & 1240 & 1260 & 1125 & 875 & 575 \\
\hline
\end{tabular}

In Tables XVIII., XIX., and XX. are given the results of three series of experiments with this specimen at one frequency $(\mathrm{T}=\cdot 0255)$, but with different initial fluxes, and in Table XXI. those of one series at the frequency for which $\mathrm{T}=\cdot 0515$, the initial flux being approximately the same as in one of the preceding series, while in Table XXII. are given the results for continuous magnetizing force also with approximately the same central flux. 
Waves of Magnetic Flux along Iron Wires.

Table XVIII.-Specimen D. $\mathrm{T}=\mathbf{0}=255$.

\begin{tabular}{|c|c|c|c|c|c|c|c|c|}
\hline \multicolumn{9}{|c|}{$\begin{array}{l}\mathrm{C}=\cdot 1697 \sin \omega t+\cdot 0296 \sin 3(\omega t-58 \cdot 6)+\cdot 0091 \sin 5(\omega t-6.5 \cdot 4) . \\
\mathrm{F}=f_{1} \sin (\omega t-\theta)+f_{3} \sin 3\left(\omega t-\theta-\beta_{3}\right)+f_{5} \sin 5\left(\omega t-\theta-\beta_{\tilde{7}}\right) .\end{array}$} \\
\hline$x$. & $f_{1}$. & $f_{3} / f_{1}$ & $f_{\bar{j}} i f_{1}$. & $\theta$. & $\beta_{3 ;}$ & $\beta_{5}$. & $\theta_{x}-\theta_{0}$. & $\lambda_{1}$. \\
\hline 0. & 16190 & .086 & .020 & $15 \cdot 77$ & 16.49 & 2988 & 0 & 02 \\
\hline $7 \cdot 3$ & $131 \check{0} 0$ & $\cdot 097$ & $\cdot 021$ & $19 \cdot 52$ & 1233 & 2698 & 375 & .0460 \\
\hline $10 \ldots$ & 11620 & $\cdot 107$ & $\cdot 021$ & $21 \cdot 19$ & $10 \cdot 56$ & 24.44 & $5 \cdot 42$ & .0414 \\
\hline $15 \ldots .$. & 9440 & $\cdot 121$ & 021 & $24 \cdot 27$ & $8 \cdot 34$ & $20 \hat{73}$ & 8.50 & .0278 \\
\hline $20 \ldots \ldots \ldots$ & 7816 & -132 & .022 & $27 \cdot 38$ & $6 \cdot 77$ & $17 \cdot 72$ & $11 \cdot 61$ & .0383 \\
\hline $25 \ldots \ldots \ldots$ & $64 \check{6} 6$ & $\cdot 141$ & 0.25 & $29 \cdot 97$ & $5 \cdot 68$ & $15 \cdot 62$ & $14 \cdot 20$ & 0396 \\
\hline $30 \ldots \ldots \ldots$ & $5: 92$ & $\cdot 151$ & 024 & $32 \div 0$ & 472 & $11 \cdot 33$ & 1673 & .0455 \\
\hline $40 \ldots$ & 3360 & $\cdot 166$ & $\cdot 033$ & $36 \cdot 39$ & $4 \cdot 17$ & $9 \cdot 86$ & $20 \cdot 62$ & 0530 \\
\hline $50 \ldots \ldots \ldots$ & 1976 & $\cdot 179$ & $\cdot 041$ & $39 \cdot 23$ & $3 \cdot 61$ & $8 \cdot 47$ & $23+46$ & 0614 \\
\hline $60 \ldots$ & 1070 & $\cdot 181$ & .045 & $40 \cdot 97$ & $4 \cdot 35$ & $8 \cdot 58$ & 2520 & .0716 \\
\hline 80. & 2554 & $\cdot 183$ & $\cdot 046$ & $41 \cdot 20$ & $5 \cdot 52$ & $9 \cdot 46$ & $25 \cdot 43$ & 06.51 \\
\hline $100 \ldots \ldots$ & $69 \cdot 5$ & $\cdot 160$ & $\cdot 0+1$ & 37.90 & 6.98 & $12 \cdot 83$ & $29 \cdot 13$ & .0501 \\
\hline $120 \ldots$ & $25 \cdot 47$ & $\cdot 147$ & .037 & $33 \cdot 38$ & $9 \cdot 14$ & $15 \div 6$ & $17 \cdot 61$ & .0381 \\
\hline $140 \ldots \ldots \ldots$ & $11 \cdot 91$ & $\cdot 133$ & $\cdot 031$ & $30 \cdot 43$ & $9 \cdot 04$ & $18 \cdot 42$ & $14 \cdot 66$ & .0270 \\
\hline $160 \ldots \ldots \ldots$ & 694 & $\cdot 145$ & .027 & $28 \cdot 40$ & $11 \cdot 32$ & $19 \cdot 95$ & $12 \cdot 63$ & .0487 \\
\hline $180 \ldots \ldots . .$. & $2 \cdot 62$ & $\cdot 135$ & $\cdot 036$ & $26 \cdot 83$ & 1252 & $19 \cdot 43$ & $11 \cdot 06$ & \\
\hline
\end{tabular}

Table XIX.—Specimen D. $\mathrm{T}=\cdot 0254$.

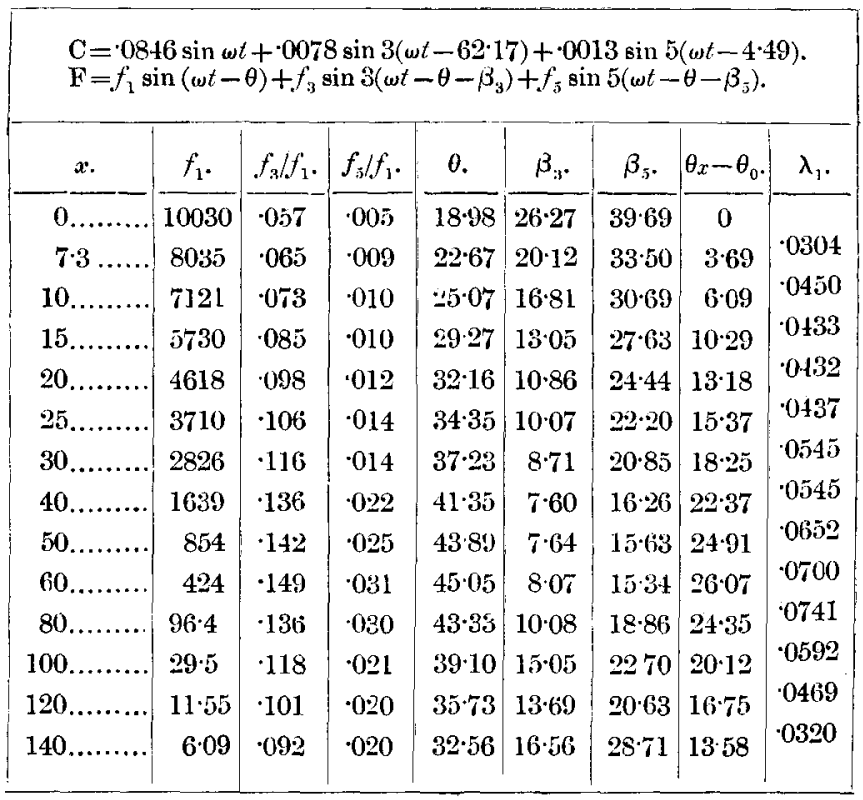


TABLE XX. - Specimen D. T $=\cdot 0255$.

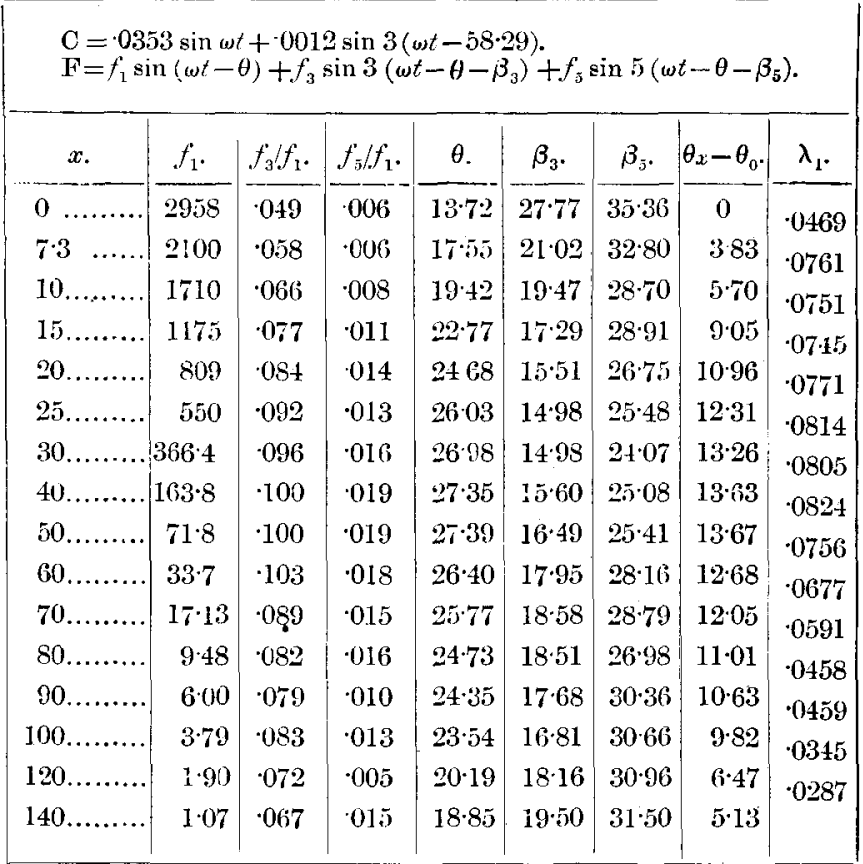

A glance at the columns for $\theta_{x}-\theta_{0}$ and $\lambda_{1}$ in Tables XVIII. to XXI. will show that so far as phase retardation and leakage caefficients are concerned, the general character of the results is the same as has been obtained from the other specimens; and, as was expected, not only are these quantities much reduced in magnitude, but also the effect of change of frequency on them is less marked. In addition the apparently coincident point of maximum phase retardation and maximum leakage coefficient is much further removed from the origin than in any of the other specimens.

13. A much more striking result, however, is the way the upper harmonics of the flux, and hence its wave form, vary as the flux-wave passes along the specimen. In these series the ratios $f_{3} / f_{1}$ and $f_{5} / f_{1}$ of the amplitudes of the third and fifth harmonics to that of the first are much larger than in the previous ones, where the flux wave was almosi sinusoidal. We were therefore able to determine for this specimen these upper harmonics both in amplitude and phase with certainty for greater distances from the origin than for the other 
Waves of Magnetic Fluar along Iron Wires.

TABLE XXI.-Specimen D. T=.0515.

$\mathrm{C}=\cdot 0790 \sin \omega t+\cdot 0050 \sin 3(\omega t-59 \cdot 46)+\cdot 0006 \sin 5(\omega t-64 \cdot 86)$.

$\mathbf{F}=f_{1} \sin (\omega t-\theta)+f_{3} \sin 3\left(\omega t-\theta-\beta_{3}\right)+f_{5} \sin 5\left(\omega t-\theta-\beta_{5}\right)$.

\begin{tabular}{|c|c|c|c|c|c|c|c|c|}
\hline$x$. & $f_{1}$. & $f_{3} / f_{1}$ & $f_{5} / f_{1}$. & $\theta$. & $\beta_{3}$. & $\beta_{i,}$. & $\theta_{x}-\theta_{0}$. & $\lambda_{1}$. \\
\hline 0 . & 9472 & 65 & 012 & 2 & $19 \cdot 80$ & $3 \because 3$ & 0 & $\cdot 030$ \\
\hline $7 \cdot 3$ & 7592 & 077 & $\cdot 013$ & 19.90 & 14.58 & $28 \cdot 61$ & 298 & .0454 \\
\hline 10. & 6700 & $\cdot 083$ & .014 & $21 \cdot 68$ & $13 \cdot 83$ & $28 \cdot 83$ & 476 & . \\
\hline 15. & 5193 & $\cdot 098$ & .017 & $25 \cdot 15$ & $10 \cdot 83$ & 2391 & $8 \cdot 23$ & 0441 \\
\hline 20. & 4167 & $\cdot 115$ & 016 & $27^{\circ}$ & 934 & $22 \cdot 38$ & $10 \cdot 86$ & .0455 \\
\hline 25. & 3310 & $\cdot 123$ & 019 & 30.09 & 881 & $17 \cdot 68$ & $13 \cdot 17$ & .051 \\
\hline 30. & 2560 & $\cdot 136$ & 022 & $32 \cdot 16$ & $8 \cdot 00$ & $17 \cdot 50$ & $15 \cdot 24$ & .059 \\
\hline $40 \ldots$ & 1414 & $\cdot 153$ & $\cdot 033$ & 36.00 & 7.75 & $15 \cdot 05$ & $19 \cdot 08$ & $\cdot 06$ \\
\hline $50 .$. & 736 & $\cdot 159$ & $\cdot 032$ & $38^{\circ}$ & & 65 & 24 & .0721 \\
\hline 60. & 358 & 165 & $\cdot 039$ & $39 \cdot 0$ & 7 & $14 \cdot 31$ & $22 \cdot 08$ & .0789 \\
\hline $70 \ldots$ & $162 \cdot 9$ & 155 & $\cdot 036$ & $38 \cdot 38$ & $8 \cdot 22$ & $14 \cdot 35$ & $21 \cdot 46$ & $\cdot 072$ \\
\hline $80 .$. & 78.7 & J & 38 & 36 & & & 99 & $\cdot 0600$ \\
\hline 100. & $23 \cdot 7$ & 131 & $\cdot 028$ & $33 \cdot 41$ & $10 \cdot 42$ & $18 \cdot 50$ & 16.49 & $\cdot 044$ \\
\hline $120 \ldots$ & 66 & $\cdot 121$ & $\cdot 026$ & $30 \cdot 06$ & $11 \cdot 16$ & 22.35 & $13 \cdot 14$ & .0333 \\
\hline $140 \ldots$ & & $\cdot 10$ & $\cdot 014$ & $28 \cdot 7$ & $12 \cdot 78$ & $19 \cdot 78$ & $11 \cdot 81$ & 026 \\
\hline $160 \ldots$ & 292 & $\cdot 099$ & -023 & $28 \cdot 26$ & $10 \cdot 25$ & $22 \cdot 50$ & $11 \cdot 34$ & $03:$ \\
\hline 170. & $2 \cdot 20$ & 099 & $\cdot 023$ & $26 \cdot 2 \bar{i}$ & 1424 & $28 \cdot 24$ & $9 \cdot 35$ & .059 \\
\hline $180 \ldots$ & $1 \cdot 13$ & $\cdot 093$ & $\cdot 020$ & $25 \cdot 65$ & $14 \cdot 62$ & $29 \cdot 63$ & $8 \cdot 73$ & \\
\hline
\end{tabular}

Table XXII.-Specimen D. Static Leak. $\mathrm{T}=\infty$.

Magnetizing Current. $\mathrm{C}=.0915$ (obs.).

\begin{tabular}{|c|c|c|c|c|c|c|c|c|c|c|c|c|c|c|c|}
\hline$x$. & 0 & $7 \cdot 3$ & 10 & 15 & 20 & 25 & 30 & 40 & 50 & 60 & 75 & 90 & 100 & 110 & 120 \\
\hline F. & 9775 & 7700 & $651 \bar{\jmath}$ & \begin{tabular}{l|l}
5235 & 4
\end{tabular} & 41.54 & 3267 & 2542 & 1429 & 740 & 355 & 120 & $45 \cdot 6$ & 269 & 158 & $11 \cdot 1$ \\
\hline$\lambda \ldots$ & .0327 & $7 \cdot 0617$ & $7 \cdot 0439$ & \begin{tabular}{c|c|c|}
9 & 0462
\end{tabular} & $2 \cdot 0481$ & $1^{1.0502}$ & $2 \cdot 0576$ & $\begin{array}{ll}6 & 0658\end{array}$ & 0735 & 0723 & 0614 & $4 \cdot 0528$ & $8 \cdot 053$ & & 531 \\
\hline
\end{tabular}

specimens; and the results given in the tables show that as we move away from the magnetizing coil we find $(a)$ that the ratios $f_{3} / f_{1}$ and $f_{5} / f_{1}$ first increase, then both attain a maximum at approximately the same place, and after this diminish, and this maximum point is the same as that at 
which the phase retardation and the leakage coefficient of the first harmonic attain their maxima; $(b)$ that the retardations in phase $\beta_{3}, \beta_{\mathfrak{y}}$ of these harmonics behind the primary first diminish, become minima, and then increase, and that the point of minimum values of $\beta_{3}$ and $\beta_{5}$ is the same apparently as that of maxima $f_{3}^{\prime} f_{1}$ and $f_{5} / f_{1}$ as well as that of maxima $\theta_{x}-\theta_{0}$ and $\lambda_{1}$. The above may be differently stated as follows:-As the flux-wave moves away from the origin its form gradually changes, becoming flatter and flatter until it reaches the point of maximum lag and maximum leakage coefficient. After this as it continues to move on its flatuess steadily diminishes. This change of form is exhibited in fig. 9, in which are plotted the two wave forms for $x=0$ and $x=60$ in the series given in Table XVIII. They are placed inaccurately as regards relative phase, but the ordinates of the one for $x=60$ are increased so that the amplitudes of the first harmonies of the two curves are the same.

Further interesting information as to the behaviour of the upper harmonics of the flux may be obtained by considering their actual amplitudes. Taking the third harmonies for any of the series in this paper, we find that the leakage coefficients are different from what we estimated they would he for a primary or first harmonic of the same amplitude and frequency at the same section of the rod. In some cases, indeed, as will be seen from the tables given, the amplitude of the third harmonic actually increases as the distance from the magnetizing coil increases.

Hence we cannot consider the upper harmonics as being independent of the first harmonic or of each other. Each seems to get continually reinforced by the first harmonic as well as by other harmonics lower in order than itself as it travels along. Such a transference of energy from the first harmonic to the higher ones must be accompanied either by a reduction of the amplitude of the first harmonic, which in these experiments would manifest itself as leakage in $\lambda_{1}$, or by a retardation of its phase helping to increase $\theta_{x}-\theta_{0}$, or by both ; so it is probable that this reinforcement of the higher barmonics by the first has an important bearing on the theory of the experiments described in this paper.

14. In order to investigate the effect of change of diameter we made two smaller bundles with wires taken from specimen D. One of these called $d_{1}$ contained 46 , and the other called $d_{2} 12$ wires, and as $\mathrm{D}$ originally consisted of 185 wires the sectional areas of $\mathrm{D}, d_{1}$, and $d_{2}$ were very nearly in the proportions of 16 to 4 to 1 or their diameters as 4 to 2 to 1 . 
One series of experiments was performed with each of $d_{1}$ and $d_{2}$ under approximately the same conditions of frequency and initial flux-density as the series already performed on $\dot{D}$ and recorded in Table XXI.

In Tables XXIII. and XXIV.are given the results of the new series, and it will be seen on comparing them with Table XXI. and with each other, that the effect of change of diameter is if anything more marked than that of permeability which was illustrated by the comparative series on specimens $\mathrm{A}$ and $\mathrm{B}$.

Thus we find that the values of $d \theta / d x$ near the origin for the diameters 4,2 , and 1 , are $4 \cdot 75,9 \cdot 9$, and $15 \cdot 3$ respectively; so that if we deduced a "velocity" from these figures we should get very different values for it, in the same material, with the same frequency and flux-density.

The change of diameter seems to have little or no effect on the max. value of the retardation, though it has a marked effect on the distance from the origin at which this maximum occurs. Thus the coincident points of max. retardation and max. leakage coefficient are at distances from the magnetizing solenoid approximately proportional to the diameters of the specimens in which they occur.

Again we find that reduction of diameter increases the leakage coefficients (for the same conditions of frequency and flux-density) approximately in the same ratio as the diameter is reduced.

Table XXIII.-46 wires from Specimen D.

$$
\mathrm{T}=\cdot 050 \text {. }
$$

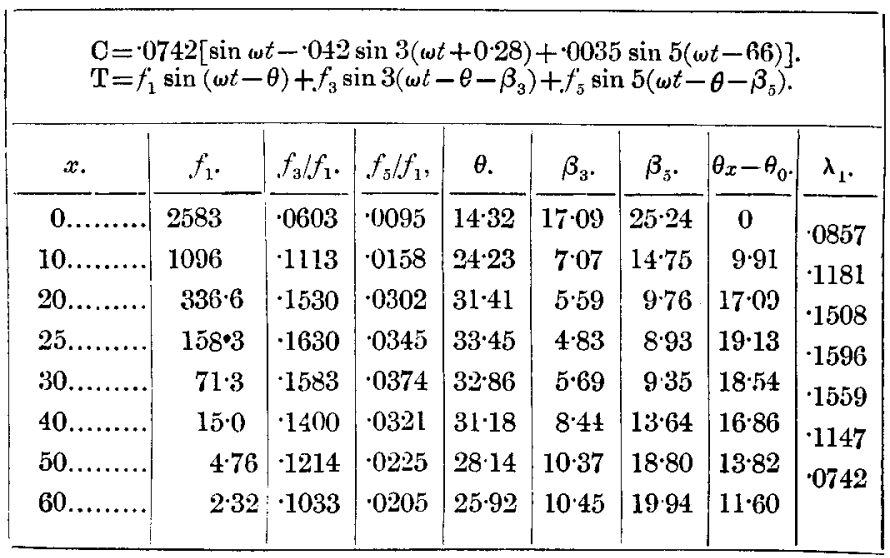


464 Prof. Lyle and Mr. Baldwin on Propagation of

TABLE XXIV.-12 wires from Specimen D. $\mathrm{T}=\cdot 050$.

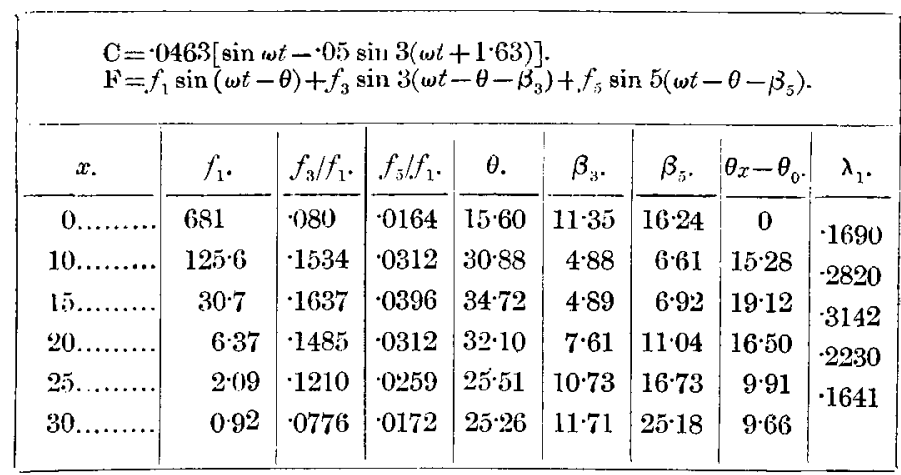

In particular it is most striking that the max. values of $\lambda_{1}$, viz.:-

$$
\cdot 3142, \cdot 15: 6 \text {, and } \cdot 0789 \text {, }
$$

should be so nearly inversely proportional to the corresponding diameters, 1, 2, and 4 respectively, the corresponding products being

$$
\cdot 3142, \cdot 3192 \text {, and } \cdot 3156 \text { respectively. }
$$

In addition we find with the smaller bundles $d_{1}$ and $d_{2}$ the same change of form of the flux-wave as it passes along them as in the case of specimen D, and also the same peculiarity in the behaviour of the upper harmonics both as regards their amplitudes and phases as has been drawn attention to in the preceding paragraph in relation to the thicker bundle.

15. The fact that so many of the characteristics of the alternating flux attain either their maximum or minimum values at practically the same point in the specimen (particularly in D, $d_{1}$, and $d_{2}$ ) is undoubtedly the most striking result of this investigation.

This point might be called the critical point for the specimen under the conditions of initial flux and frequency used, its distance from the magnetizing solenoid the critical distance, and the values of the ditferent characteristics of the flux there the critical values. For the existence of such a critical point we are unable to offer any explanation.

A more fundamental knowledge than any we at present possess of the nature of magnetization and permeability is required. Our want of any exact knowledge of the amplitude and phase relations between induction and magnetizing force and of the relations between the different harmonics of an 
induction wave precludes the possibility of a satisfactory solution on the basis of our present knowledge.

16. It was thought, however, that a partial explanation of some of the phenomena observed might be obtained if the initial flux was made up of elementary magnetic lines very heterogeneous as regards their phases. As these passed along the specimen there would be a retardation of the phase of each line due to "velocity" as well as a change of the phase of the resultant flux at any section due to groups of lines in special phases leaking out at special distances from the origin. If this were so, the phases of the lines at different distances from the axis of the rod or bundle should be different, as at any section those lines about to leak out would be near its circumference. To test this the wires of specimen $\mathrm{D}$ were divided into three groups. The first group of 28 wires was taped to form a circular cylinder, and round it was wound a search-coil of 50 turns insulated. Over this central cylindrical bundle the second group of 45 wires was uniformly distributed and taped so that the whole formed a circular cylinder coaxial with the first. An insulated search-coil of 50 turns was wound round the middle of the compound bundle formed. The remaining group of 110 wires was now added and taped so as to be coaxial with the others, and a third search-coil of 50 turns was wound round the middle of the whole.

The bulging caused by the search-coils was not very great. The magnetizing coil was wound on a bobbin, and could be placed at any distance on the specimen from the search-coils. By means of a switch the search-coils could be connected in different ways, so that when continued to the wave-tracer the latter determined for us the flux-waves through the central bundle or through either of the surrounding tubular bundles of wires for different distances from the magnetizing coil.

The result of this investigation was to show that while at the centre of the magnetizing coil the flux-density and phase varied over the section-the phase of the first harmonic for the outer layer being 4.56 degrees ahead of that for the central portion and the amplitude varying from 67 lines per wire for the outside portion to 58.5 lines per wire for the central,yet for distances greater than $15 \mathrm{cms}$. from the magnetizing coil there was no appreciable difference in the phases of the first harmonics, wave-forms, or densities of the fluxes through the three different portions of the compound bundle. Hence no such explanation as that imagined at the beginning of this paragraph can be tenable.

17. It was also thought that if we determined in amplitude and phase the magnetizing force required to produce the

Phil. Mag. S. 6. Vol. 12. No. 71. Nov. 1906. $2 \mathrm{H}$ 
different resultant fluxes at different sections of the specimen in any one series of the transmission experiments, we might obtain some information that would help to explain the phenomena.

This was done for specimen $\mathrm{A}$ and for a cylindrical bundle made up of 46 of the iron wires from specimen D.

The specimen was inserted in a long solenoid and by means of the wave-tracer, using it as described in a former paper* by one of us, the amplitudes and phases of the magnetizing forces required to produce uniform oscillating fluxes of different amplitudes and phases were obtained and the results plotted. From these curves and the results given in this paper on specimen $A$, and similar results obtained from the narrow bundle, we were able to obtain the amplitude and phase of the resultant magnetizing force that acted at each section of the specimens in the transmission experiments. When these characteristics of the magnetizing force were plotted against corresponding distances along the specimen from the magnetizing solenoid, the curves obtained were less instructive than those for the characteristics of the flux at different distances which have been given in this paper.

18. To sum up :-When waves of magnetic flux that have been started by alternating currents in a short solenoid placed at the centre of a long iron rod, or bundle of iron wires, are transmitted along the rod or bundle, we find that-

(1) The retardation of phase of the first harmonic of the flux at any point distant $x$ from the centre, behind the first harmonic of the initial flux, first increases with $x$, attains a maximum and then diminishes, and keeps diminishing until the flux is dissipated if the specimen is sufficiently long for this to be effected.

(2) The leakage coefficient $\lambda_{1}$ of the amp. $f_{1}$ of the first. harmonic, which we define by the equation $\lambda_{1}=-\frac{1}{f_{1}} \frac{d f_{1}}{d x}$, first increases with $x$, attains a maximum, and then diminishes and keeps diminishing until the flux is dissipated.

(3) The distances from the magnetizing solenoid at which the phase retardation and the leakage coefficient become maxima are equal (or very nearly so), and the point at which these maxima occur we call the critical point of the specimen, and its distance from the magnetizing solenoid the critical distance, for the particular initial flux and frequency used.

(4) Previous investigators of this subject, using less sensitive methods, were only able to obtain observations within the

*T. R. Lyle, "Variation of Magnetic Hysteresis with Frequency," Phil. Mag, vol, ix. p. 102 (1905). 
critical distance, and from their observations concluded (1) that the leakage coefficients were practically constant at all distances $x$, thus arriving at a logarithmic decrease of flux amplitude; (2) that the fairly regular space-rate of phase retardation $d \theta / d x$ observed would be completely accounted for by a velocity of magnetization $v$, deduced by the formula

$$
v=\frac{2 \pi}{\mathrm{T} d \theta / d x} .
$$

We find that neither of these conclusions is correct, as (a) $\lambda$, for the same rod and conditions of experiment, varies within wide limits along the rod, and (b) the retardation, after increasing as they observed within the critical distance, becomes stationary at the critical point, beyond which the phase of the flux advances : so that if their conclusion (2) were correct, we should have to admit an infinite relocity at the critical point and a negative velocity beyond it.

(5) As the flux passes along the specimens made of wires, the amplitudes $f_{3}, f_{5}$ of its upper harmonics get continually reinforced by a transference of energy from the first harmonic (see $\$ 13$, Tables XVIII.-XXI.). The ratios $f_{3} / f_{1}, f_{5} / f_{1}$ first increase with $x$, attain maxima, and then diminish; at the some time the differences $\beta_{3}, \beta_{5}$ between the phases of these harmonies and the phase of the first diminish first with $x$, attain minima, and then increase; and the positions of maxima of $f_{3} / f_{1}, f_{5} / f_{1}$ and minima of $\beta_{3}, \beta_{5}$ are at (or near) the critical point. From this it results that as the flux-wave moves away from the origin its form changes, becoming flatter as $x$ increases (see fig. 9) until the critical point is reached, when its flatness is a maximum; beyond this as $x$ increases its flatness diminishes.

(6) The effects of an end on a flux-wave approaching it are to increase the leakage coefficient and to cause an advance in the phase. (See fig. b.)

(7) When a rod whose behaviour has been determined is shortened and subjected to the same magnetization as before, no difference is observed in the flux-waves until (for a $\frac{1}{4}$ in. rod) within $30 \mathrm{cms}$. from the new end. (See $\$ 8$ and fig.6.)

(8) For the same frequency, initial flux, and cross-section, increase of permeability increases the critical distance, in, creases the critical value of the retardation (see fig. 7), and diminishes the critical value of the leakage coefficient. (See $\S 9$ and fig. 8).

(9) Eddy currents diminish the critical distance, increase the critical value of the retardation, and increase the leakage coefficients. (See § 12.) 
(10) For the same frequency, initial fux-density, and material, increase of diameter of the specimen increases the critical distance, has little or no effect on the critical retardation (hence making $d \theta / d x$ near the origin less), and diminnishes the leakage coefficients : in fact, we find that the critical distance is approximately proportional to the diameter, and the critical value of the leakage coefficient inversely proportional to the diameter. (See $§ 14$ and Tables XXI., XXIII., XXIV.)

(11) For the same specimen and initial flux, increase of frequency increases the initial value of $d \theta / d x$, increases the critical values of the retardation and the leakage coefficient, and slightly diminishes the critical distance. (See figs. 1, 2, and the Tables.)

(12) For the same specimen and frequency, increase of initial flux increases the critical distance (see fig. 4), increases the critical value of the retardation (fig. 4), and reduces the critical value of the leakage coefficient (see fig. 5): also for low values of the initial flux $\mathrm{F}_{0}, d \theta / d x$ near the origin increases with $F_{1}$, but seems to approach an upper limit for high values of $\mathrm{F}_{0}$. (See fig. 4.)

L. On the Use of Chilled Cast Iron for Permanent Magnets. By Albert Campbell, B.A. (From the National Physical Laboratory.)*

GARLY in the past year an interesting paper $\dagger$ was D published by Mr. B. O. Peirce of Harvard University, drawing attention to the fact that chilled cast-iron is in many instances a suitable material for permanent magnets. As the subject is of interest to scientific experimenters and of considerable imporlance to instrument makers, I undertook some time ago a short research upon it, with a view, firstly of obtaining some measurements by standard methods, and secondly of finding, if possible, an easy method of chilling the material so as to give good results.

Form of Test Pieces. - The cast iron tested was of ordinary commercial quality and was obtained in the form of rods and rings. The rods, which were of rectangular section, were shaped to dimensions usual in such tests, viz., $10 \mathrm{~cm} . \times$ $1 \mathrm{~cm} . \times 1 \mathrm{~cm}$.

* Communicated by the Physical Society : read January 26, 1906.

† Amer. Acad. Proc. xl. 22. pp. 701-715, April 1905. Dr. Watson has kindly drawn my attention to Mr. J. R. Ashworth's experiments on chilled cast-iron rods (Proc. Roy. Soc. vol. Ixii. p. 210, Dec. 9, 1897); he found that the magnetic quality of these was comparable with that of tungsten steel. 